\title{
II. Frauen als Autorinnen und Wissenschaftlerinnen und die Neuere deutsche Literaturwissenschaft - Christine Touaillon (1878-1928)
}

Christine Touaillon gehörte im Wintersemester 1897/98 zu den ersten Studentinnen der Universität Wien und war 1921 die erste österreichische Germanistin, die als Privatdozentin zugelassen wurde. ${ }^{1}$ Ihre Bildungslaufbahn lässt jene Brüche erkennen, die angesichts des sich wandelnden Mädchenschulwesens im letzten Drittel des 19. Jahrhunderts für Frauen aus bildungsbürgerlichen Familien ${ }^{2}$ nicht untypisch waren: Touaillon besuchte in ihrer Jugend nicht weniger als fünf verschiedene Schulen, ${ }^{3}$ bis sie schließlich im Sommer 1897 die zu diesem Zeitpunkt höchste mögliche Ausbildung, die k.k. Lehrerinnenbildungsanstalt des Zivilmädchenpensionats in Wien, absolvierte und als Volksschullehrerin zu arbeiten begann. ${ }^{4}$ Im Herbst desselben Jahres wurden Frauen aber auch an der Wiener Universität zum Studium zugelassen und Touaillon schrieb sich sogleich als eine von insgesamt 37 Studentinnen ein, um, wie sie 1919 rückblickend feststellte, „Litteraturgeschichte zu studieren, was ich seit früher Kindheit

1 Das folgende Kapitel beruht zum Teil auf einem bereits publizierten Aufsatz; Grabenweger: „Ein durch und durch weibliches Buch“ (2010).

2 Touaillons Vater Leopold Auspitz gehörte als Generalmajor zu den ranghöheren Offizieren der k.k. Armee und war ein Vertreter des liberalen Lagers, das der durch Königgrätz augenscheinlich gewordenen - Krise des Militärs mit dem Ideengut des aufklärerischen Josephinismus und den Bildungsidealen des aufstrebenden Bürgertums zu begegnen versuchte. - Zu Touaillons Familie vgl. das Typoskript ihres Bruders Walther Heydendorff: Kurzgefaßte Familiengeschichte; ÖStA, Kriegsarchiv, Nachlass Heydendorff, B/844/11. Zur politischen Ausrichtung der k.k. Armee vgl. Allmayer-Beck: Die bewaffnete Macht in Staat und Gesellschaft (1987).

3 Volksschule in St. Pölten, Volksschule in Salzburg, Bürgerschule in St. Pölten, Bürgerschule in Wien, Höhere Töchterschule in Wien, Lehrerinnenbildungsanstalt in Wien. - Die Ortswechsel lassen sich mit dem Beruf des Vaters erklären, der häufige Schulwechsel innerhalb Wiens war der Umgestaltung des Bildungswesens geschuldet, da Touaillon immer dann die Schule wechselte, wenn sich bessere, d. h. höhere Bildungsmöglichkeiten für Mädchen eröffneten.

4 An der Volksschule Notre Dame de Sion in Wien. 
leidenschaftlich gewünscht hatte“" ${ }^{\text {" Erst }} 1902$ holte sie als Externistin am k.k. Obergymnasium Salzburg die Reifeprüfung nach. ${ }^{6} 1904$ wechselte sie, nachdem sie den in der Steiermark tätigen Notar Heinrich Touaillon geheiratet hatte, für ein Jahr an die Grazer Universität, wo sie bei Rudolf Meringer, Anton Emanuel Schönbach und Bernhard Seuffert studierte. Zurück in Wien besuchte sie - nun als ordentliche Hörerin - Lehrveranstaltungen bei Richard Heinzel, Robert Franz Arnold, Max Hermann Jellinek und Alexander von Weilen, vor allem aber die Seminare Jakob Minors, bei dem sie 1905 mit der Arbeit Zacharias Werners „Attila, König der Hunnen " 7 als vierte Frau an der Wiener Germanistik auch promovierte (und als dessen letzte Schülerin sie gelten kann). ${ }^{8}$

Nach ihrem Studium war Touaillon in zahlreichen gesellschafts- und sozialpolitischen Belangen der späten österreichisch-ungarischen Monarchie tätig. Von 1910 bis 1918 gab sie gemeinsam mit Leopoldine Kulka und Emil Fickert die feministische Zeitschrift Neues Frauenleben heraus. Darüber hinaus veröffentlichte sie in den 1900er und 1910er Jahren zahlreiche Artikel zu gesellschaftspolitischen und literarischen Themen in der sozialdemokratischen Arbeiterinnen-Zeitung ${ }^{10}$ sowie in verschiedenen

5 Eigenhändiger Lebenslauf von Christine Touaillon vom 15. Mai 1920; UAW, Phil. Fak., PA 3462 Christine Touaillon.

6 Erst 1901, vier Jahre nach Zulassung von Frauen zur Universität, wurde ein Erlass verabschiedet, der es ermöglichte, an Mädchenschulen die Reifeprüfung inklusive Studienberechtigung zu erwerben. Bis 1911 bestand aber ein Ausnahmepassus, der Frauen ein dreijähriges Universitätsstudium erlaubte, ihnen die Promotion jedoch verwehrte; außer sie legten - wie Touaillon - zwischenzeitlich als Privatistinnen die Reifeprüfung an einem Knabengymnasium ab. Vgl. Heindl: Zur Entwicklung des Frauenstudiums in Österreich (1990), S. 23-24; Engelbrecht: Geschichte des österreichischen Bildungswesens. Bd. 4 (1986), S. 291-292.

7 Ein Exemplar ihrer handschriftlichen Dissertation befindet sich in der Universitätsbibliothek Wien unter ihrem Mädchennamen. Auspitz: Zacharias Werners „Attila, König der Hunnen“ (1904).

8 So Körner: Deutsche Philologie [1935], S. 83 - Vor Touaillon promovierten an der Wiener Germanistik folgende Frauen: Helene Munz (Arnims „Gräfin Dolores", 1903), Rosa Fliegelmann (Achim von Arnims „Halle und Jerusalem“, 1903) und Antonie Hug von Hugenstein (Zur Textgeschichte von Novalis Fragmenten, 1904).Biographische Informationen zu Touaillon laut ihren eigenhändigen Lebensläufen vom 24. Juni 1919; UAG, Phil. Fak., Z. 1529 ex 1919; und vom 15. Mai 1920; UAW, Phil. Fak., PA 3462 Christine Touaillon.

9 Touaillon wurde die Nachfolgerin von Auguste Fickert, die ihr 1908 die Redaktion des Literaturblatts überantwortet hatte. Vgl. Hacker: Wer gewinnt? Wer verliert? Wer tritt aus dem Schatten? (1996).

10 Vgl. u.a. Touaillon: Das Wahlrecht und die Frauen (1919). 
Zeitschriften wie Wissen für alle, Dokumente des Fortschritts, Der Kunstwart und Die Gegenwart. ${ }^{11}$ Außerdem war Touaillon Vorstandsmitglied des Allgemeinen Österreichischen Frauenvereins, ${ }^{12}$ Ausschussmitglied der Ethischen Gemeinde in Wien ${ }^{13}$ und Vizepräsidentin der Internationalen Liga für Frieden und Freiheit. ${ }^{14} \mathrm{Zu}$ ihrem sozialen Umfeld gehörten Vertreterinnen der bürgerlichen Frauenbewegung wie Auguste Fickert ${ }^{15}$ und Rosa Mayreder ${ }^{16}$ ebenso wie der Reformpädagoge und spätere ordentliche Professor für Philosophie an der Universität Wien Wilhelm Jerusalem und der Arzt und Vorkämpfer der Friedensbewegung in Österreich Wilhelm Börner. ${ }^{17}$ Während des Ersten Weltkriegs organisierte Touaillon pazifistische Veranstaltungen ${ }^{18}$ und nach 1918 engagierte sie sich - als vehemente Unterstützerin einer sozial ausgerichteten demokratischen Staatsverfassung - in der österreichischen Sozialdemokratischen Arbeiterpartei vor allem für Otto Glöckels Bildungsreformen. ${ }^{19}$ Als man ihr 1919 in der Steiermark zweimal ein Landtagsmandat anbot, lehnte sie jedoch ab - mit dem Hinweis, dass sie „nicht 3 Dinge leisten kann (Ehe, Wissenschaft u Politik)“20.

11 Vgl. u. a. Touaillon: Zur Psychologie des Familienblattes (1905); dies.: Ein Revolutionsroman (1910); dies.: Die Lage der Telephonistinnen (1911); dies.: Ferdinand von Saars Altersdichtung und die Moderne (1911); dies.: Der Schrei nach dem Genie (1911); dies.: Emil Marriot [d.i. Emilie Mataja], Der abgesetzte Mann [Rez.] (1912).

12 [Anonym:] Vereinsvorstand 1917 [des Allgemeinen Österreichischen Frauenvereins] (1918).

13 Mayreder: Christine Touaillon [Nekrolog] (1928).

14 Internationale Frauenliga für Frieden und Freiheit, Zweig Österreich; Institut für Geschichte der Universität Wien, Sammlung Frauennachlässe, NL. I/39a, 523-1 4.

15 Vgl. die Briefe Touaillons im Nachlass von Auguste Fickert in der Wienbibliothek im Rathaus.

16 Vgl. die Briefe Touaillons im Nachlass von Rosa Mayreder in der Wienbibliothek im Rathaus.

17 Vgl. die Briefe Touaillons im Nachlass von Wilhelm Börner in der Wienbibliothek im Rathaus.

18 Lebensaft: Christine Touaillon (2002), S. 758. Zu Touaillons Antikriegshaltung vgl. auch Touaillon: Weltkrieg (1914).

19 „Ich war vorgestern in einer Glöckel-Versammlung - schade, daß Du nicht da warst: Du wärst zwar nicht einverstanden gewesen, aber Du hättest begriffen, was mich auf diese Seite zwingt." Brief von Christine Touaillon an Walther Heydendorff vom 10. März 1920; ÖStA, Kriegsarchiv, Nachlass Heydendorff, B/844/13.

20 Brief von Christine Touaillon an Walther Heydendorff, o.D. [19. April 1919]; ÖStA, Kriegsarchiv, Nachlass Heydendorff, B/844/13. 
Tatsächlich verfolgte Touaillon zu diesem Zeitpunkt andere Pläne. Bereits 1910, nachdem sie ihre Forschungen über ältere deutsche Kinderliteratur aufgrund der schwierigen Materialbeschaffung in der steirischen Provinz unterbrechen musste, ${ }^{21}$ hatte sie begonnen, an einer großen wissenschaftlichen Studie über Schriftstellerinnen des 18. Jahrhunderts zu arbeiten. ${ }^{22}$ Ohne auf Vorarbeiten zurückgreifen zu können, aber mit der Unterstützung des Grazer Universitätsprofessors Bernhard Seuffert sowie von „[s] echzehn reichsdeutsche[n] Bibliotheken“23, die ihr - trotz Ersten Weltkriegs - Bücher zugeschickt hatten, stellte sie 1918 ihre über 650 Seiten umfassende Arbeit Der deutsche Frauenroman des 18. Jahrhunderts fertig, um, wie sie ihrem Bruder schrieb, „mit 41 noch [...] mit etwas Neuem zu beginnen (Dozentur), obwohl ich eine Frau bin! ${ }^{\text {24 }}$ Ganz einfach dürfte dieses Unterfangen aber schon vor Antragstellung an der Universität nicht gewesen sein: Nachdem Touaillon in Wilhelm Braumüller einen Verleger gefunden hatte, scheiterte die Drucklegung ihres Buchs nämlich am Papiermangel zu Beginn der Ersten Republik. Schließlich erklärte sich eine Grazer Fabrik bereit, „2000 Kilo Papier gegen Lieferung von 300 Kilo Schweine abzugeben“, deren Beschaffung, wie Rosa Mayreder am 19. März 1918 in ihrem Tagebuch notierte, Touaillon „[m]it Hilfe befreundeter Bauern“ auch gelang. ${ }^{25}$ Das Buch erschien sodann - in bemerkenswert schöner Aufmachung mit rotem Oberleinen und Schmutzumschlag - im Juni 1919 und Touaillon machte sich sogleich auf, einen Teil der österreichischen Universitätslandschaft mit ihrem Ansinnen $\mathrm{zu}$ beschäftigen. ${ }^{26}$

21 Eigenhändiger Lebenslauf Touaillons vom 15. Mai 1920; UAW, Phil. Fak., PA 3462 Christine Touaillon; vgl. auch Kluckhohn: Christine Touaillon [Nekrolog] (1928), S. 23. - Die Ergebnisse ihrer Studien veröffentlichte Touaillon unter: Literarische Strömungen im Spiegel der Kinderliteratur (1912).

22 Eigenhändiger Lebenslauf Touaillons vom 15. Mai 1920; UAW, Phil. Fak., PA 3462 Christine Touaillon.

23 Eigenhändiger Lebenslauf Touaillons vom 24. Juni 1919; UAG, Phil. Fak., Z. 1529 ex 1919.

24 Brief von Christine Touaillon an Walther Heydendorff vom 1. August 1919; ÖStA, Kriegsarchiv, Nachlass Heydendorff, B/844/13.

25 Mayreder: Tagebücher 1873-1937 (1988), S. 178.

26 „Dieser Tage erhielt ich die ersten Ex. m. Buches u morgen reiche ich ein. Es wird ein sehr interessanter Kampf werden; hoffentlich siege ich!" Brief von Christine Touaillon an Walther Heydendorff vom 24. Juni 1919; ÖStA, Kriegsarchiv, Nachlass Heydendorff, B/844/13. 


\section{II.1. Zwischen Universität und Staatsverfassung - Habilitationsverfahren in Graz und Wien}

Ihr erstes Gesuch um „Erteilung der Lehrbefugnis für neuere deutsche Litteraturgeschichte" reichte Touaillon am 24. Juni 1919 an der Universität Graz ein. Dem Schreiben lag eine beglaubigte Kopie ihrer Promotionsurkunde, ihre im selben Monat erschienene Monographie Der deutsche Frauenroman des 18. Jahrhunderts, ein Lebenslauf und ein Programm ihrer für die ersten Semester geplanten Vorlesungen bei. In genauer Kenntnis der geltenden Habilitationsbestimmungen und vor dem Hintergrund der im Entstehen begriffenen politischen und rechtlichen Gleichstellung von Frauen und Männern durch die Verfassung der Ersten Republik erklärte Touaillon, dass sie „somit die Bedingungen erfüllt [habe], welche die Verordnung des k.k. Min. für Kultus u Unterricht vom 11.2.1888, betreffend die Habilitierung von Privatdozenten, stellt ${ }^{\text {“27 }}$.

Wie aus einem von Touaillon am 30. Juni 1919 verfassten Nachtrag zum Habilitationsgesuch hervorgeht, versuchte das Professorenkollegium der Grazer philosophischen Fakultät jedoch bereits nach wenigen Tagen den Antrag Touaillons aus formalen Gründen zurückzuweisen. Zum einen wollte man ihr unter Hinweis auf ihren Geburtsort Iglau/Jihlava in Mähren die österreichische Staatsbürgerschaft absprechen $;^{28}$ darauf antwortete Touaillon, dass sie, da sie als „Frau [...] die Zuständigkeit des Gatten teilt", „dennoch nach Deutschösterreich zuständig" sei. ${ }^{29}$ Zum anderen versuchte das Professorenkollegium darin, dass ihr Wohnort nicht Graz, sondern Stainz war, einen Verstoß gegen die Habilitationsordnung zu sehen. ${ }^{30}$ Dem setzte Touaillon folgende Erklärung entgegen:

27 Habilitationsgesuch von Christine Touaillon vom 24. Juni 1919; UAG, Phil. Fak., Z. 1529 ex 1918/19.

28 Die österreichische Staatsbürgerschaft war für die Habilitation zu dieser Zeit eigentlich nicht verpflichtend. Erst die ständestaatliche Verordnung von 1934 änderte die geltende Habilitationsnorm dahingehend ab, dass der Staatsbürgerschaftsnachweis erbracht werden musste. Verordnung des Bundesministeriums für Unterricht [...] vom 23. Mai 1934 [...] betreffend die Zulassung und die Lehrtätigkeit der Privatdozenten an den Hochschulen (Habilitationsnorm) (1934).

29 Nachtrag zum Habilitationsgesuch vom 30. Juni 1919; UAG, Phil. Fak., Z. 1529 ex 1918/19.

30 In der noch 1919 geltenden Habilitationsordnung vom 11. Februar 1888 heißt es in $\$ 14$, dass die ,venia docendi erlischt, wenn ein Privatdocent [...] seinen ordentlichen Wohnsitz außerhalb des Sitzes der Universität unter solchen Umständen verlegt, dass die regelmäßige Abhaltung von Vorlesungen seitens desselben nicht gewärtigt werden kann“. Verordnung des Ministers für Cultus und Unter- 
Mein Wohnort [...] ist nur $26 \mathrm{~km}$ von Graz entfernt u besitzt täglich dreimalige Zugsverbindung mit Graz $\left(5^{\mathrm{h}} 30,9^{\mathrm{h}} 47,4^{\mathrm{h}} 47\right)$. Ich wäre also sogar in der Lage, täglich zu kommen u von einer Unmöglichkeit regelmäßige Vorlesungen abzuhalten, kann gar keine Rede sein. ${ }^{31}$

Daraufhin ging das Professorenkollegium in seiner Sitzung am 11. Juli 1919 - auf Antrag des Archäologen und Prodekans Rudolf Heberdey dazu über, die Behandlung des Gesuchs durch Vertagung zu verzögern, mit dem Argument, dass der Erlass eines neuen Privatdozentengesetzes abzuwarten sei. ${ }^{32}$ Tatsächlich war zu dieser Zeit in Österreich eine neue Habilitationsordnung in Ausarbeitung. Doch ungeachtet der Bemühungen um diese neue Regelung, die erst am 2. September 1920 in Kraft trat, ${ }^{33}$ wurden Habilitationsanträge von Männern weiterhin verhandelt. Im Studienjahr 1919/20 wurde allein an der philosophischen Fakultät der Universität Graz vier Wissenschaftlern die Venia Legendi verliehen. ${ }^{34}$

Dass die Weigerung der philosophischen Fakultät in Graz, Touaillons Antrag überhaupt zu verhandeln, nichts mit der geltenden Gesetzeslage zu tun hatte, zeigte sich spätestens, als sich im Oktober desselben Jahres auch die staatliche Unterrichtsbehörde mit dem Thema zu beschäftigen begann. Am 18. Oktober 1919 forderte der damalige Unterstaatssekretär für Inneres und Unterricht Otto Glöckel alle österreichischen Universitäten dazu auf, zur „Zulassung von Frauen zur Privatdozentur“ Stellung zu nehmen. Glöckel selbst vertrat in seinem Schreiben die Absicht, „den Frauen hinsichtlich der Erlangung der venia docendi an den weltlichen Fakultäten der Universitäten grundsätzlich die volle Gleichberechtigung mit männlichen Habilitationswerbern einzuräumen". 35

richt vom 11. Februar 1888 betreffend die Habilitirung [!] der Privatdozenten an Universitäten (1888).

31 Nachtrag zum Habilitationsgesuch vom 30. Juni 1919; UAG, Phil. Fak., Z. 1529 ex 1918/19.

32 Protokoll der 8. ordentlichen Sitzung des Professorenkollegiums der philosophischen Fakultät vom 11. Juli 1919 (Schriftführer: Richard Meister); UAG, Phil. Fak., Z. 1640 ex 1918/19.

33 Vollzugsanweisung des Staatsamtes für Inneres und Unterricht vom 2. September 1920, betreffend die Zulassung und die Lehrtätigkeit der Privatdozenten an den Hochschulen (Habilitationsnorm) (1920).

34 Dem Psychologen Othmar Sterzinger, dem Mathematiker Roland Weizenböck, dem Mineralogen Franz Angel und dem Chemiker Alois Zinke. Habilitationsausweis der philosophischen Fakultät für das Studienjahr 1919/20; UAG, Phil. Fak., Z. 2007 ex 1919/20.

35 Brief von Otto Glöckel an die österreichischen Universitäten vom 18. Oktober 1919; UAG, Rek., Z. 474 ex 1918/19. 
Die vom Grazer Rektor Otto Cuntz in dieser Angelegenheit eingeholten Gutachten der theologischen, juristischen, medizinischen und philosophischen Fakultät lassen an Deutlichkeit nichts zu wünschen übrig. Die theologische Fakultät lehnte in ihrer Sitzung vom 24. November 1919 die Zulassung von Frauen zur Privatdozentur einstimmig und mit nur einem Satz ab. ${ }^{36}$ Eine Begründung findet sich im betreffenden Sitzungsprotokoll nicht. Dafür ist auf dem Brief des Rektors an die theologische Fakultät, die genau genommen vom Ministerium als einzige gar nicht angesprochen war, von fremder Hand eine Art Rechtfertigung notiert. Darin heißt es, dass „Frauen, wie die allgemeine Erfahrung zeigt, in wissenschaftlichen Arbeiten mit den Männern nicht konkurrieren können, trotzdem sie Gelegenheit genug gehabt haben, sich wissenschaftlich zu betätigen". Geschlossen wird diese kurze Notiz mit der Abwandlung eines Bibelzitats: „Mulier taceat non solum in Ecclesia, sed etiam in Universi-

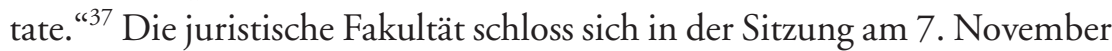
1919 dem Antrag Gustav Hanauseks, „sich grundsätzlich gegen die Zulassung auszusprechen", knapp, aber doch, mit fünf gegen vier Stimmen, an. ${ }^{38}$ Die medizinische Fakultät sprach sich gegen eine „regelmässig[e]“ Zulassung aus, erhob aber „keine prinzipiellen Bedenken gegen die Bewerbung in ganz ausnahmsweisen Fällen “ ${ }^{39}$

Die philosophische Fakultät beschäftigte sich mit dem Thema um einiges ausführlicher als die bereits genannten, war sie auch die einzige, der tatsächlich das Habilitationsgesuch einer Frau vorlag. Die eigens eingesetzte Kommission, bestehend aus dem Physiker Hans Benndorf, den beiden Germanisten Bernhard Seuffert und Karl Polheim, den Biologen Karl Linsbauer und Rudolf Scharfetter sowie dem Historiker Heinrich von Srbik, beschloss, „dass von weiblichen Kandidaten der Nachweis des gesicherten wissenschaftlichen Rufes als unentbehrliche Voraussetzung der

36 Protokoll der 2. ordentlichen Sitzung des Professorenkollegiums der theologischen Fakultät vom 24. November 1919 (Schriftführer: Anton Michelitsch); UAG, Theol. Fak., Z. 118 ex 1919/20.

37 Notiz auf dem Brief des Rektors Cuntz an die theologische Fakultät vom 30. Oktober 1919; UAG, Theol. Fak. Z. 73 ex 1919/20. - „Die Frau soll nicht nur in der Kirche, sondern auch an der Universität schweigen." (Originalzitat aus 1. Korinther 14,34: „Mulieres in ecclesiis taceant“.)

38 Protokoll der 2. ordentlichen Sitzung des Professorenkollegiums der rechts- und staatswissenschaftlichen Fakultät vom 7. November 1919; UAG, Jur. Fak., Z. 303 ex 1919/20.

39 Stellungnahme der medizinischen Fakultät, o.D.; UAG, Med. Fak., Z. 300 ex 1918/19. 
Habilitation gefordert werden müsse“. Diese „Erschwerung gegenüber den für männliche Bewerber bestehenden Bedingungen" begründete die Kommission in einem ausführlichen Gutachten folgendermaßen:

Die im Zuge der modernen Entwicklung im politischen Leben durchgeführte Gleichstellung der Frau mit dem Manne kann nicht ohne weiteres auf akademische Verhältnisse übertragen werden, denn sie hat Gleichheit der wissenschaftlichen Begabung der beiden Geschlechter weder zu ihrer Voraussetzung noch bietet ihre Durchführbarkeit eine Gewähr für die positive Entscheidung dieser für die Zulassung von Frauen zum akademischen Lehramte ausschlaggebenden Frage. [...]

Die Erfahrungen, die mit weiblichen Studierenden seit ihrer Zulassung zu den Universitätsstudien gemacht wurden, lassen jedoch tatsächliche Unterschiede in der durchschnittlichen Begabung von Frauen und Männern erkennen. Dem weiblichen Geschlechte kommt im allgemeinen eine sehr gute Anlage zur receptiven Aufnahme des dargebotenen Wissens und sehr viel Strebsamkeit und Fleiß zu, die Originalität und besonders die Selbständigkeit des Denkens aber, die sich auch der Autorität des Lehrers gegenüber durchsetzt, sind bei Frauen viel seltener als bei Männern zu finden. Auch scheint noch nicht festzustehen, ob die Eignung der Frau für alle Wissensgebiete eine gleichmäßige ist. So ist die Frage, ob die Beurteilung historischer Verhältnisse durch die Psyche der Frau von demselben Range ist, wie die des Mannes, noch offen.

Die charakteristischen Unterschiede in dem Typus der durchschnittlichen Begabung erklären, daß auch eine gute Arbeit, die unter dem frühen Eindruck des Universitätsstudiums und unter dem Einfluß eines Docenten entstanden und durchgeführt ist, bei Frauen in viel geringerem Grade als bei ihren männlichen Kollegen die sichere Gewähr für den Besitz gerade jener Eigenschaften gibt, die für den Forscher und für den Lehrer die wertvollsten sind.

In der Tat sind Originalität und Selbständigkeit des Denkens die wesentlichsten Bedingungen nicht allein für erfolgreiche produktive Arbeit sondern auch für den akademischen Unterricht, der nicht in der Wiedergabe der Ergebnisse der Wissenschaft allein bestehen darf, der vielmehr erst aus deren Verarbeitung durch die persönliche Eigenart des Docenten Wert und Bedeutung erlangt.

[...] Will man zu einem begründeten Urteil über die Eignung einer Frau zu dem akademischen Lehramte gelangen so müssen bindende Beweise gefordert werden, da die Gefahr eines Irrtums in der Beurteilung der Eignung zum akademischen Lehramte bei Frauen näher liegt als bei Männern. ${ }^{40}$

Diese Stellungnahme der philosophischen Fakultät ist aus mehreren Gründen bemerkenswert. Zunächst zog die Kommission eine klare Trennlinie zwischen politischen und akademischen Belangen und insistierte auf einer Nichtübertragbarkeit verfassungsmäßiger Gleichheits-

40 Stellungnahme der philosophischen Fakultät zur Zulassung von Frauen zur Privatdozentur o.D. [2. Dezember 1919]; UAG, Phil. Fak., Z. 558 ex 1919/20. 
grundsätze auf das universitäre Feld. Den Grund dafür sah die Kommission in einem spezifisch akademischen Kapital: dem der wissenschaftlichen Begabung. Während die gesellschaftliche und politische Entwicklung unabhängig von diesem Kapital vonstattengehen, sei es für die Entwicklung des Wissenschaftsbetriebs aber unerlässlich. Und genau an diesem Kapital, dessen Beurteilung allein dem akademischen Feld zu obliegen habe und das gleichzeitig die Grundbedingung der Zugehörigkeit zu eben diesem Feld darstelle, orientierte sich die weitere Argumentation der philosophischen Fakultät. Zunächst argumentierte sie auf der Ebene der Erfahrung. So habe das Frauenstudium gezeigt, dass eindeutige „Unterschiede in der durchschnittlichen Begabung von Männern und Frauen" auszumachen seien. In Übereinstimmung mit der Auffassung der, Geschlechtscharaktere ${ }^{\text {(41 }}$ würden sich diese Unterschiede vor allem darin zeigen, dass Frauen rezeptiv, also nachahmend, und Männer produktiv, also selbständig, dächten. In einem nächsten Schritt wurde darauf aufbauend festgestellt, dass selbst „eine gute Arbeit" einer Frau - im Unterschied zu einer guten Arbeit eines Mannes - nicht unbedingt von ihrer wissenschaftlichen Befähigung zeuge, da man nicht mit Sicherheit feststellen könne, ob sie der Originalität und Selbständigkeit des Denkens oder dem „Einfluß eines Docenten“ zu verdanken sei. Da aber gerade „Originalität und Selbständigkeit die wesentlichsten Bedingungen" sowohl für die wissenschaftliche Arbeit als „auch für den akademischen Unterricht“ darstellen, sei es notwendig, bei Frauen über die übliche wissenschaftliche Qualifikation hinausgehende „bindende Beweise“ für ihre akademische Eignung zu fordern. Wie diese „bindenden Beweise“ und der „Nachweis des gesicherten wissenschaftlichen Rufes" genau zu erbringen seien, ließ das Gutachten jedoch offen. ${ }^{42}$

Dass sich das Professorenkollegium der philosophischen Fakultät der Universität Graz bezüglich der Zulassung von Frauen zur Privatdozentur nicht einig war, zeigte die Sitzung vom 5. Dezember 1919. In dieser Sitzung

41 Zur Vorstellung der, Geschlechtscharaktere` vgl. Kap. II.2.

42 Alle Zitate: Stellungnahme der philosophischen Fakultät zur Zulassung von Frauen zur Privatdozentur, o.D. [2. Dezember 1919]; UAG, Phil. Fak., Z. 558 ex 1919/20. - Für Österreich fehlen bislang vergleichende Untersuchungen; für Deutschland stellt Stefanie Marggraf aber fest, dass die „Formel der prinzipiellen Zulassung von Frauen unter Sonderkonditionen " für Habilitationsverfahren in der Weimarer Republik charakteristisch sei, da die „Zulassung von Frauen zur Habilitation [...] nicht als Gebot der Chancengleichheit, sondern als Ausnahmeregelung für Höchstleistungen gesehen" wurde. Marggraf: Sonderkonditionen (2002), S. 40-41. 
wurde das Gutachten zwar angenommen, jedoch ,nur' mit zwanzig gegen zehn Stimmen. Für den Rektor Otto Cuntz, der als Altphilologe ebenfalls dem philosophischen Professorenkollegium angehörte, drückte das Gutachten nicht explizit genug eine ablehnende Haltung aus, weshalb er forderte, dass sich „die Fakultät [grundsätzlich] gegen die Zulassung der Frauen zur Habilitation“ ausspreche. ${ }^{43}$ Da dieser Antrag mit 16 gegen 14 Stimmen abgelehnt wurde, fügte er dem Gutachten einen Nachtrag hinzu, in dem er „starke Bedenken“ äußerte, „ob Frauen überhaupt im Stande sind, auf junge Männer [...] den erforderlichen persönlichen pädagogischen Einfluß zu nehmen“. ${ }^{44}$

Machen schon die einzelnen Stellungnahmen der Fakultäten keinen Hehl daraus, dass sie der Habilitation von Frauen, wenn nicht klar ablehnend, dann doch zumindest ziemlich skeptisch gegenüberstanden, so fügte der Akademische Senat in dem auf der Basis der einzelnen Stellungnahmen verfassten offiziellen Gutachten, das am 18. Februar 1920 dem Ministerium für Inneres und Unterricht übermittelt wurde, noch eine weitere ablehnende Argumentationslinie hinzu:

Die Frage, ob Frauen zur Privatdozentur zuzulassen sind, ist nicht vom Standpunkte des, eine petitio principii enthaltenden Schlagwortes der öffentlich-rechtlichen Gleichberechtigung der Frauen mit den Männern und auch nicht vom Standpunkte einzelner hervorragend begabter Frauen aus zu beurteilen. Die Frage ist vielmehr die, ist es vom Standpunkte der Universität wertvoll, wenn Frauen die venia legendi an Universitäten erteilt werden kann. Diese Frage ist auch von denjenigen, die wissenschaftliche Arbeiten von Frauen hoch einschätzen, für die ungeheure Mehrzahl der Fälle, also grundsätzlich zu verneinen.

Bei objektiver Beurteilung wird man gewiss nicht behaupten dürfen, dass die bisherige Ausschliessung der Frauen von der Privatdozentur die wissenschaftliche Stellung unserer Universitäten irgendwie beeinträchtigt hätte. ${ }^{45}$

Otto Glöckel, der Unterstaatssekretär für Inneres und Unterricht, unterstrich gegenüber der Grazer Universität seine Forderung nach der Gleichstellung von Männern und Frauen bei Habilitationsverfahren

43 Protokoll der 3. ordentlichen Sitzung des Professorenkollegiums der philosophischen Fakultät vom 5. Dezember 1919 (Schriftführer: Franz Faltis); UAG, Phil. Fak., Z. 580 ex 1919/20.

44 Handschriftliche Notiz des Rektors Otto Cuntz vom 8. Dezember 1919 auf der Stellungnahme der philosophischen Fakultät zur Zulassung von Frauen zur Privatdozentur, o.D. [2. Dezember 1919]; UAG, Phil. Fak., Z. 558 ex 1919/20.

45 Da das betreffende Gutachten im Universitätsarchiv Graz nicht auffindbar ist, wird hier zit. n. Kernbauer: Die ersten akademischen Lehrerinnen (1996), S. 194. 
mehrmals. ${ }^{46}$ Doch trotz dieser Bemühungen und trotz des Verstoßes der dargestellten Gutachten und Stellungnahmen gegen den verfassungsmäßigen Gleichheitsgrundsatz der Ersten Republik setzte sich die Universität Graz mit einem von ihr postulierten Autonomieanspruch gegenüber der staatlichen Unterrichtsbehörde durch. ${ }^{47}$ Mit Autonomie meinte die Universität jedoch nicht die Freiheit von Forschung und Lehre, sondern das Recht zu bestimmen, wer Teil des universitären Systems sein durfte und wer nicht. ${ }^{48}$ Erst 1932 wurde an der Universität Graz der ersten Frau, der Historikerin Mathilde Uhlirz, die Venia Legendi verliehen. Davor hatte Uhlirz bereits 1916 und 1921 um Habilitation angesucht, beide Male wurden ihre Anträge jedoch abgelehnt. ${ }^{49}$ Christine Touaillon zog nach Interventionen beim Ministerium ${ }^{50}$ ihren Antrag am 3. Oktober 1920 zurück. ${ }^{51}$ Bereits fünf Monate zuvor hatte sie aber an der Wiener philosophischen Fakultät ein zweites Gesuch eingereicht, das schließlich auch erfolgreich war. ${ }^{52}$

In Wien hatte das Professorenkollegium der philosophischen Fakultät Ende 1919 ganz anders als in Graz auf das Schreiben Otto Glöckels reagiert. In einem äußerst knapp gehaltenen Kommissionsbericht vom 21. November 1919 „legt[e]“ die Fakultät „Wert darauf zu betonen“,

dass sie bereits vor längerer Zeit für Frauen, welche denselben Bedingungen entsprachen wie männliche Habilitationswerber, die Venia legendi beantragt hat. ${ }^{33}$ Sie handelt daher nur konsequent, wenn sie, der Anregung des Staat-

46 Rainer Leitner: Christine Touaillon, geb. Auspitz (1991), S. 36-37.

47 Die Rechtfertigung eines Autonomieanspruchs gegenüber der staatlichen Unterrichtsbehörde beschäftigte zu Beginn der Ersten Republik alle Universitäten des Landes. Vgl. Höflechner: Die österreichische Rektorenkonferenz (1993).

48 Aufgrund des Versuchs des Bildungsreformers Glöckel, Einfluss auf alle Bereiche des Unterrichtswesens zu nehmen, sprach man an den Universitäten abschätzig von der ,Verglöckelung' des Bildungswesens. Höflechner: Die Baumeister des künftigen Glücks (1988), S. 115.

49 Zu Mathilde Uhlirz' Habilitationsverfahren vgl. Höflechner: Mathilde Uhlirz (1996). - Die erste Germanistin in Graz, der die Venia Legendi verliehen wurde, war Beatrix Müller-Kampel; sie habilitierte sich 1993.

50 Dass sich Touaillon mit Glöckel persönlich verständigte, geht aus ihren Briefen an ihren Bruder Walther Heydendorff hervor. Vgl. v. a. ihre Briefe an ihn vom 24. April 1919, 5. Mai 1919, 9. Mai 1919 und 25. Mai 1919; ÖStA, Kriegsarchiv, Nachlass Walther Heydendorff B/844/13.

51 Brief von Touaillon an das Dekanat der philosophischen Fakultät in Graz vom 3. Oktober 1920; UAG, Phil. Fak., Z. 72 ex 1920/21.

52 Habilitationsantrag von Touaillon vom 15. Mai 1920; UAW, Phil. Fak., Zl. 939 ex 1920/21, PA 3462 Christine Touaillon.

53 Gemeint ist die Romanistin Elise Richter, die sich 1907 in Wien habilitierte. 
samtes für Unterricht Folge gebend, bereit ist, Frauen und Männer unter den gleichen Bedingungen zur Habilitation zuzulassen. ${ }^{54}$

Dass es sich bei dieser Stellungnahme nicht um eine diplomatisch-unverbindliche Antwort an die staatliche Unterrichtsbehörde handelte, zeigt die zwar zögerliche, insgesamt aber wohlwollende Haltung gegenüber Touaillons Ansinnen. Touaillon hatte die Spielregeln des Feldes gelernt und auf mehreren Ebenen Druck ausgeübt, bevor sie in Wien tatsächlich um die Verleihung der Lehrbefugnis ansuchte. Wie aus einem Brief Touaillons vom 29. November 1920 an August Sauer in Prag hervorgeht, vergewisserte sie sich zunächst bei den Wiener Professoren, dass diese ihre Habilitationsschrift Der deutsche Frauenroman des 18. Jahrhunderts annehmen und ihrem Gesuch stattgeben werden. Nach der Zustimmung des Altgermanisten Max Hermann Jellinek verhandelte Touaillon mit Walther Brecht, den sie, wie sie Sauer schrieb, ,nach harten Mühen zu den strikten Erklärungen [brachte], daß er [ihr] Buch als genügende Grundlage für [ihre] Habilitation ansehe, daß er keine weitere Arbeit verlange und überhaupt mit [ihrer] Habilitation einverstanden sei." $\mathrm{Zu}$ bedenken gab Brecht allerdings, dass die „Gefahr [bestünde], daß andere Professoren das Buch für eine Tendenzschrift halten würden". ${ }^{55}$ Nachdem sich Touaillon daraufhin auch noch der Zustimmung des Romanisten Karl von Ettmayer und des Anglisten und damaligen Dekans der philosophischen Fakultät Karl Luick versichert hatte, schickte sie am 15. Mai $1920 \mathrm{ihr}$ Gesuch ab. Gleichzeitig mit den Verhandlungen und Gesprächen mit den Wiener Entscheidungsträgern kümmerte sie sich um Rezensionen für ihr Buch, damit es dem Professorenkollegium „schwer gemacht würde, es abfällig zu beur-

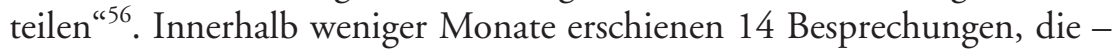
mit einer Ausnahme - allesamt günstig ausfielen. Besonders die Rezension ihres Beraters August Sauer im Euphorion hielt umfassend und ausführlich dazu an, dass sich alle späteren Rezensionen an ihr orientieren. In genauer Kenntnis der akademischen Lage deklinierte Sauer in seiner Rezension jene

54 Kommissionsbericht betreffend der Habilitation von Frauen an der philosophischen Fakultät der Universität Wien vom 21. November 1919; UAW, Phil. Fak., S 03 Frauenstudium (Erlässe).

55 Brief von Touaillon an Sauer vom 29. Februar 1920; Wienbibliothek im Rathaus, Nachlass August Sauer, ZPH 103.

56 Brief von Touaillon an Sauer vom 29. Februar 1920; Wienbibliothek im Rathaus, Nachlass August Sauer, ZPH 103. Vgl. auch den Brief von Touaillon an Elise Richter vom 8. März 1920; ÖNB, Handschriftensammlung; 266/47-1: „Mein Buch wird durchaus günstig besprochen; die Fachautoritäten wie Sauer, Köster, Waldberg haben sich erst brieflich, da aber höchst anerkennend geäußert." 
Vorbehalte durch, die gegen das Thema der Habilitationsschrift und die Wissenschaftlerin ins Feld geführt werden könnten, und entkräftete sie sogleich. ${ }^{57}$

Nach diesen, auf persönlichen Einflussnahmen beruhenden Vorbereitungen traf Touaillons Habilitationsantrag auf eine Kommission ${ }^{58}$, die, zumindest laut Sitzungsprotokollen, kein Wort darüber verlor, dass über die Habilitation einer Frau verhandelt wurde. Touaillons Habilitationsschrift wurde als „[r]espektable Leistung“ mit „[g]ute[r] Fragestellung“ (Brecht) bezeichnet, ihr selbst eine „sehr gründliche Bildung“ (Jellinek) attestiert und auch von ihrer „Persönlichkeit“ hatte die Kommission einen "guten Eindruck" (Brecht, Much). ${ }^{59}$ Die aus den erhaltenen Akten hervorgehende Diskussion war hauptsächlich von den teilweise konträren Ansichten des Professorenkollegiums über den Charakter idealtypischer Wissenschaft bestimmt. Dabei stand die Frage der innerfachlichen Differenzierung im Mittelpunkt: Nämlich, ob Touaillon die Lehrbefugnis für das ganze Fach oder ob ihr, wie es ohnehin bereits Usus war, im Interesse der weiteren institutionellen Etablierung eines Teilgebiets die Venia Legendi nur für die neuere Abteilung verliehen werden sollte. ${ }^{60}$ Nach Habilitationskolloquium und Probevortrag über „Die Entwicklung der deutschen Kinderliteratur" sprach sich das Professorenkollegium der philosophischen Fakultät am 18. Juni 1921 für die Verleihung der Lehrbefugnis für „neuere deutsche Literaturgeschichte“ aus, worüber das $\mathrm{Mi}$ nisterium am 30. Juni 1921 informiert wurde. ${ }^{61}$ Zwei Wochen später, am

57 Sauer: Christine Touaillon, Der deutsche Frauenroman des 18. Jahrhunderts [Rez.] (1921). Zu den Rezensionen vgl. auch Kap. II.2.

58 Der Kommission, die am 14. Juni 1919 von Dekan Karl Diener (Geographie) einberufen wurde, gehörten die Germanisten Walther Brecht, Rudolf Much, Max Hermann Jellinek und Robert Franz Arnold sowie Karl Ettmayer (Romanische Philologie), Paul Kretschmer (Sprachwissenschaft), Edmund Hauler (Klassische Philologie), Oswald Redlich (Geschichte), Friedrich Becke (Mineralogie) und Karl Luick (Englische Philologie) an.

59 Protokoll des Kommissionssitzung betreffend das Gesuch von Dr. Christine Touaillon um Erteilung der Venia legendi für neuere deutsche Literaturgeschichte vom 7. Dezember 1920; UAW, Phil. Fak., Zl. 939 ex 1920/21, PA 3462 Christine Touaillon.

60 Protokoll des Kommissionssitzung betreffend das Gesuch von Dr. Christine Touaillon um Erteilung der Venia legendi für neuere deutsche Literaturgeschichte vom 7. Dezember 1920; UAW, Phil. Fak., Zl. 939 ex 1920/21, PA 3462 Christine Touaillon.

61 Brief des Dekanats an das Ministerium für Inneres und Unterricht vom 30. Juni 1921; ÖStA, AVA, Unterricht allgemein, Philosophie Professoren, MCU Zl. 14978 ex 1921, PA Christine Touaillon. 
10. Juli 1921, wurde der Beschluss vom Ministerium bestätigt. ${ }^{62}$ Damit war Christine Touaillon die erste habilitierte Germanistin und 14 Jahre nach der Romanistin Elise Richter die zweite habilitierte Frau in Österreich.

\section{II.2. Literatur-, Kultur- und Sozialgeschichte - Der deutsche Frauenroman des 18. Jahrhunderts (1919)}

Mit ihrer Habilitationsschrift Der deutsche Frauenroman des 18. Jahrhunderts (1919) trat Christine Touaillon mit einem Unterfangen in die universitäre Germanistik ein, das in wissenschaftsgeschichtlicher Hinsicht sowohl in seiner Themenstellung und in seiner methodischen Vorgehensweise als auch in seiner (innerfachlichen) Rezeption bemerkenswert ist. Die Wahl des Themas bedurfte zeitgenössisch einer eingehenden Erklärung und Verteidigung. Gleich zu Beginn ihrer umfassenden Untersuchung wehrte sich Touaillon dagegen, dass ihr Buch nicht als wissenschaftliche Analyse, sondern als zweckgebundener und parteiischer Beitrag zur Frauenbewegung gelesen werde. Das Vorwort eröffnete sie demgemäß mit folgenden Worten:

So überflüssig es bei einer wissenschaftlichen Arbeit erscheint, ihre Tendenzlosigkeit zu betonen, so legt der Titel des Buches doch die Befürchtung nahe, es werde für eine Tendenzschrift gehalten und - je nach Parteistellung des Lesers - mit einem günstigen oder ungünstigen Vorurteil in die Hand genommen werden. In Wirklichkeit glaube ich so objektiv gewesen zu sein, als ein Mensch überhaupt objektiv sein kann: weit über dem Geschlecht steht mir die Wissenschaft. ${ }^{63}$

Doch nicht nur die vermutbare Nähe ihres Buchs zur Frauenbewegung bzw. zu programmatischen Zielen einer feministischen Geschlechterpolitik versuchte Touaillon - durch eine klare Abgrenzung von wissenschaftlichem und gesellschaftspolitischem Feld - zu entkräften, sondern auch die Position ihres Themas innerhalb des wissenschaftlichen Feldes selbst er-

62 Brief des Bundesministeriums für Inneres und Unterricht an das Dekanat der philosophischen Fakultät vom 10. Juli 1921; UAW, Phil. Fak., Zl. 939 ex 1920/21, PA 3462 Christine Touaillon.

63 Touaillon: Der deutsche Frauenroman des 18. Jahrhunderts (1919), S. VII. - Im Folgenden im Fließtext zitiert als (Touaillon 1919, [Seitenangabe]). 
schien ihr rechtfertigungsbedürftig. So stellte sie fest, dass es „unmöglich [sei], den Frauenroman vom Männerroman ${ }^{64}$ völlig zu trennen“:

Nur scheinbar setzt der Titel dieser Arbeit eine solche Trennung voraus. In Wirklichkeit ist die Geschichte des Frauenromans nur ein Kapitel der Gesamtgeschichte des Romans, aus dieser herausgehoben, weil der deutsche Frauenroman des 18. Jahrhunderts bisher überhaupt keine Beachtung durch die Literaturgeschichte erfuhr. (Touaillon 1919, 3)

Was Touaillon hier 1919 ihren Fachkollegen vorschlug, war eine bislang vernachlässigte, ihres Erachtens aber notwendige Ergänzung und somit auch Vervollständigung der bisherigen Literaturhistoriographie (auf deren Status in der zeitgenössischen Germanistik noch zurückzukommen sein wird). Gleichzeitig hatte diese alternative Literaturgeschichtsschreibung aber auch ihre eigene Überwindung zum Ziel und somit programmatischen Charakter. Es sollte durch Integration in die allgemeine, d.h. zeitgenössisch männliche Geschichte des Romans überflüssig werden, den Frauenroman getrennt darzustellen. ${ }^{65}$ Es läge nahe, Touaillons Rechtfertigung nicht nur als explizite Benennung eines Desiderats der Literaturgeschichtsschreibung, sondern auch als ausdrückliche Kritik an der bislang innerhalb der Germanistik vorgenommenen Auswahl an Forschungsbereichen und als Frontstellung gegen ihre männlichen Fachkollegen zu lesen. Wie noch zu zeigen sein wird, bedeutete die Themenwahl Touaillons zeitgenössisch aber eher die Einschreibung in ein bislang unbesetztes und somit auch konkurrenzfreies Forschungsgebiet.

Der Aufbau des Buchs folgt - gemäß Touaillons Auffassung, dass der Frauenroman denselben Prinzipien wie der Männerroman gehorcht - dem bis heute üblichen Epochenschema von Literaturgeschichten: In vier Abschnitten unterscheidet sie den empfindsamen, den rationalistischen und den klassizistischen Frauenroman sowie romantische Elemente im deutschen Frauenroman. Für die Empfindsamkeit bespricht Touaillon vor allem Sophie von La Roche und ihren Roman Geschichte des Fräuleins von Sternheim, aber auch weniger bekannte Autorinnen wie Eleonore Thon, Meta Liebeskind und Friederike Lohmann. Den rationalistischen Frau-

64 Touaillon verstand unter ,Frauenromanen ‘ von Frauen, unter ,Männerromanen ‘ von Männern geschriebene Romane. Diese Begriffe werden im Folgenden, wenn nicht anders gekennzeichnet, in dieser Bedeutung von mir übernommen.

65 Dabei handelte es sich um eine Forderung, die mit der erneuten Konjunktur des Begriffs ,Frauenliteratur' erst wieder in den 1970er Jahren, also ein halbes Jahrhundert nach Touaillon, inneruniversitär vertreten wurde. Vgl. dazu Weigel: Frau und „Weiblichkeit“ (1984). 
enroman teilt Touaillon in Gegenwarts- und Vergangenheitsroman; als Verfasserinnen von Gegenwartsromanen bespricht sie Maria Sagar (als einzige Österreicherin), Barbara Knabe, Helene Unger, Benedicte Naubert, Sophie Tresenreuter, Helmine Wahl, Karoline von Wobeser, Sophie Ludwig, Amalie Ludecus, Wilhelmine Neuenhagen, Isabella von Wallenrodt und Therese Huber; als Vertreterinnen des Vergangenheitsromans geht Touaillon abermals, diesmal ausführlich auf Naubert ein, nennt aber auch Sophie Albrecht, Elisabeth Hollmann und Friederike Henriette Kühn. Der klassizistische Roman wird angeführt von Caroline von Wolzogen, gefolgt von Charlotte Kalb und Sophie Mereau, bevor sie im letzten Kapitel zur Romantik auf Dorothea Schlegel und die zu Lebzeiten unbeachtete, von Touaillon aber als Ausnahmeerscheinung gehandelte Autorin Karoline Auguste Fischer eingeht, der sie bereits vier Jahre vor Erscheinen ihrer Habilitationsschrift einen Aufsatz in der Festschrift für Wilhelm Jerusalem gewidmet hat. ${ }^{66}$

Recherchiert hat Touaillon all diese Autorinnen samt der von ihnen verfassten Romane (Touaillon geht auf die beachtliche Anzahl von über 240 von Frauen im 18. Jahrhundert geschriebenen Romanen ein) sowohl in Nachschlagewerken wie Karl Goedekes 1856 begründetem und bis heute fortgeführtem Grundriß zur Geschichte der deutschen Dichtung und Carl Schindels dreibändigem Lexikon Die deutschen Schriftstellerinnen des 19. Jahrbunderts (1823-1835) als auch anhand der Durchsicht zeitgenössischer Literaturzeitschriften und veröffentlichter sowie in Archiven aufbewahrter Briefwechsel kanonisierter männlicher Schriftsteller wie Christoph Martin Wieland, Friedrich Schiller und Clemens Brentano. Das dadurch angesammelte Material erklärt Touaillon nach einem Prinzip der Literaturgeschichtsschreibung, das ebenso aufwendig gewesen sein dürfte wie die Quellensuche selbst. Wie Sebastian Meissl zu Recht feststellte, folgte Touaillon dem „methodische[n] Leitsatz, wonach Literatur aus der Summe ihrer historischen Bedingungen zu erklären sei “67. Gleichzeitig und dem scheinbar widersprechend argumentiert Touaillon aber auch immer wieder in der Hierarchie stereotyp angenommener, Geschlechtscharaktere ${ }^{6}{ }^{68}$

66 Touaillon: Karoline Auguste Fischer (1915).

67 Meissl: Germanistik in Österreich (1981), S. 477.

68 Touaillon benutzt diesen Begriff selbst; vgl. Touaillon: Der deutsche Frauenroman des 18. Jahrhunderts (1919), S. 621 und S. 625. - Zu Definition und Vorstellungsrahmen dieses Begriffs vgl. Hausen: Die Polarisierung der ,Geschlechtscharaktere' (1976). 
Ihre Ausführungen eröffnet Touaillon mit einem Überblick über die Geschichte des deutschen Männerromans, der sie eine umfassende Sozialgeschichte der Frau vom Mittelalter bis ins 18. Jahrhundert folgen lässt, um schließlich zum eigentlichen Thema, den „unmittelbaren Entstehungsursachen des deutschen Frauenromans" (Touaillon 1919, 57-66), zu kommen: Zu diesen zählt sie nicht, wie es Ende der 1910er Jahre innerhalb der Germanistik en vogue gewesen wäre, ein überpersönliches abstraktes Entwicklungsschema oder einen geistesgeschichtlichen, unhintergehbaren Weltlauf, sondern konkrete, historisch fass- und erklärbare Konstellationen. So sei die Konzentration des Rationalismus auf Bildung und Belehrung für einen ersten Zugang von Frauen zur literarischen Produktion verantwortlich gewesen; vor allem durch den großen Erfolg der Moralischen Wochenschriften, die über ein halbes Jahrhundert „die Bildung und die Weltanschauung der deutschen Frau" (Touaillon 1919, 57) prägten. Die um 1750 aufkommende Briefleidenschaft wiederum ermöglichte, dass Frauen „außerhalb der Literatur eine schriftstellerische Technik von nicht geringer Bedeutung" (Touaillon 1919, 58) erwerben konnten, und führte zudem - durch in Zeitschriften abgedruckte Leserbriefe und Briefwechsel mit berühmten Männern - zu einer ersten Berührung mit der (literarischen) Öffentlichkeit. Auch der Pietismus habe, wenngleich "ganz gegen seine Absicht“, das „Wesen der Frau für Kunst aufgeschlossen, indem er das ganze Leben auf die Grundlage des Gefühls stellte" (Touaillon 1919, 61). Als dritte Ursache nennt Touaillon einen Wandel im Verhalten ,gelehrter Männer', die, wie Christian Fürchtegott Gellert, Johann Christoph Gottsched oder Johann Jakob Bodmer, begannen, Frauen explizit zur Schriftstellerei anzuhalten und damit neben das „Ideal der Hausfrau“ auch das „Ideal der gebildeten und geistig freien Frau“ (Touaillon 1919, 62) treten ließen.

Doch nicht nur gesellschaftliche Veränderungen seien für den Zugang von Frauen zur Literatur verantwortlich gewesen, sondern auch Transformationen im künstlerischen Feld selbst: Durch die Entstehung des Familienromans sei „eine neue Epoche der deutschen Literatur" angebrochen, die „zum erstenmal die Frau zum Stoff der Dichtung“ (Touaillon 1919, 63) werden ließ: Hatte der literarische Stoff durch seine Konzentration auf Kämpfe, Irrfahrten und Abenteuer davor jahrhundertelang den Frauen das „Eindringen in die Dichtung erschwert“, so ging es in ihr jetzt um „das selbsterlebte Nahe“ (Touaillon 1919, 64), wodurch auch die Frau als Leserin gewonnen werden konnte und damit zu einem (ökonomisch) relevanten Faktor auf dem Buchmarkt wurde. Gleichzeitig erleichterten das geringe Prestige des Romans, die einfache, poetologisch nicht explizit 
festgelegte Sprache und der Briefroman als bevorzugte Form, dass sich nicht nur Laien, sondern auch Frauen zum ersten Mal in einer nennenswerten Zahl am literarischen Schaffen beteiligen konnten. In der Kapitelzusammenfassung legt Touaillon auch gerade darauf Wert, dass nicht unbedingt die ,Begabung' der Frau die Ursache für ihren bisherigen Ausschluss aus der literarischen Produktion darstellte, sondern die Verfasstheit der Literatur selbst: „Als der Roman die Familie zu seinem Stoff, den Brief zu seiner Form machte, hatte sich die Kunst den Frauen genähert und so entstand der deutsche Frauenroman." (Touaillon 1919, 66)

Wie Touaillon bei ihrer Darstellung der einzelnen Schriftstellerinnen im Detail vorgeht, lässt sich an ihren umfassenden Erläuterungen zu Sophie von La Roche zeigen, die 1771 mit der Geschichte des Fräuleins von Sternheim nicht nur als erste Frau überhaupt als Romanschriftstellerin an die Öffentlichkeit trat, sondern gleichzeitig auch den ersten empfindsamen Roman schuf. Zunächst entwirft Touaillon La Roches Biographie, wobei Elternhaus, Ehe, Kinder, die gesellschaftliche und ökonomische Stellung sowie die Beurteilung durch Zeitgenossen ebenso breiten Raum einnehmen wie Beteuerungen, dass ihre „Dichtung [...] schon in der Kindheit [...] im Keime vorgebildet" gewesen sei. Das zeige sich daran, dass La Roche - wie Touaillon einem Brief der Autorin an Christoph Martin Wieland entnimmt - bereits mit sechs Jahren die „beiden Hauptelemente ihrer Handlung“, den „Kuß und die Träne“, zu ihren bevorzugten Ausdrucksmitteln erklärte. (Touaillon 1919, 71-72)

Nach streng philologischen Untersuchungen zu Entstehungsgeschichte und Textgenese der Geschichte des Fräuleins von Sternheim widmet sich Touaillon der Einflussforschung. So beruhe die Handlung des Romans zum ersten Mal in der Geschichte der Literatur fast durchgehend auf theologischer, insbesondere pietistischer Grundlage. Die drei Stufen (Versuchung - Erniedrigung - Erhöhung), nach denen das Leben der Heldin aufgebaut sei, entsprächen dem Grundschema des christlichen Mythos; die "große Wichtigkeit, welche die Dichterin der Verzweiflung ihrer Heldin beilegt" (Touaillon 1919, 104), lasse den Einfluss des pietistischen Theologen August Hermann Francke erkennen, der die Verzweiflung als einzig möglichen Weg zu echtem Christentum ansah. Aber auch viele weitere pietistische Ideen fänden sich in La Roches Roman: die „Wendung [...] gegen das Weltleben“, die „Forderung des geduldigen Ertragens von Trübsal, Angst und Spott", die "Sehnsucht nach einem Leben in Friede und Freundschaft mit jedermann" und nicht zuletzt die Überzeugung, dass „gute Handlungen viel ruhmwürdiger als die feinsten Gedanken" seien. Neben dem Pietismus hatten, laut Touaillon, aber auch, 
vor allem für das „Äußere der Handlung“, Motive des älteren deutschen Romans (Verkleidung, Missverständnisse, Gefangenschaft etc.) und Motive des englischen Familienromans (heimliche Heirat, Gefährdung der Tugend etc.) Einfluss auf La Roches Schaffen, wobei offensichtliche Ähnlichkeiten mit Samuel Richardsons Romanen Pamela (1740) und Clarissa (1748) auszumachen seien. (Touaillon 1919, 105)

Vorgängerfunktion habe die Geschichte des Fräuleins von Sternheim aber auch in der Anlage der Figuren; so besitze der Held Lord Seymour „Wertherzüge vor dem Werther" und die Heldin sei schon zeitgenössisch als „neuer und exotischer Typus“ eingeschätzt worden. (Touaillon 1919, 107 108) Lord Seymour findet im Liebeskummer seine einzige Befriedigung, er „klagt statt zu handeln“, ist unentschlossen und fühlt, dass „seine Empfindungen ihm gefährlich werden“; Sophie von Sternheim wiederum hat bereits ein „empfindsames Äußeres“, sie ist „nicht mehr vollkommen schön“, beeindruckt aber mit einem „Gesicht voll Seele“. (Touaillon 1919, 108) Gleichzeitig weise der Roman auch die für die Empfindsamkeit „typische Unterscheidung zwischen männlicher und weiblicher Empfindsamkeit" auf: Während die Heldin trotz ihrer Konzentration auf die Vorgänge in ihrem Inneren immer gefasst und gütig bleibt, ist Lord Seymour stets „schwermütig bis zur Zerrissenheit“. Außerdem finden sich in dem Roman die für die Empfindsamkeit charakteristischen „Männertränen“, die „Liebe auf den ersten Blick“, ein „Übermaß an Empfindungen“, das „Gefühl der Unzulänglichkeit des Lebens“, das „Motiv der Krankheit aus Kummer" und nicht zuletzt eine Vielzahl an empfindsamen Briefen, die immer und überall geschrieben werden. (Touaillon 1919, 110)

Auch in der Technik des Romans sieht Touaillon einen klaren Fortschritt gegenüber den Vorgängern der Sternheim: So fehle die „Sucht nach Spannung" (Touaillon 1919, 112), die den heroisch-galanten Roman kennzeichne, und der zusammenfassende und aufklärende Erzähler, der durch den rationalistischen Roman führe, ebenso wie die für beide typischen undurchsichtigen Verwicklungen und Versteckspiele zugunsten eines klaren, übersichtlichen und kunstvoll gestalteten Aufbaus. Selbst die von Richardson übernommene Brieftechnik habe La Roche durch das Weglassen der Antwortschreiben dahingehend modifiziert, dass eine klare Straffung der Darstellung zu erkennen sei. Bezüglich der Sprache könne der Roman, wie schon Ende des 18. Jahrhunderts der Theologe und Bonner Professor für Literatur Eulogius Schneider und im 19. Jahrhundert auch 
Erich Schmidt betonten, ${ }^{69}$ als „klassisches Muster für die Knappheit des Stils" (Touaillon 1919, 114-115) bezeichnet werden. Dabei sei aber, wie Touaillon betont, ein „Mangel zur Quelle des Vorzugs“ geworden: Dass La Roche den epischen Fluss nicht durch theologische, philosophische oder politische Erörterungen unterbrach, führt Touaillon nämlich darauf zurück, dass es dem „weiblichen Geist“ (Touaillon 1919, 112) noch nicht möglich war, Konflikte zu abstrahieren. Und auch dass in La Roches Roman zum ersten Mal „das Seelische so unverkennbar den Kern der Handlung “ bildet, dass tatsächlich von einem „empfindsamen Roman im Gegensatz zu den rationalistischen Familienromanen [...], bei denen das familiäre Milieu wichtiger ist als das Gefühl“" (Touaillon 1919, 115-116), gesprochen werden könne, erklärt Touaillon mit geschlechtsspezifischen Zuschreibungen: So habe La Roche den Roman als „Trost für den eigenen Seelenschmerz", als „Flucht aus dem Leben“ geschrieben und damit „das Fühlen [zur] wichtigste[n] Grundlage dichterischer Arbeit" (Touaillon 1919, 116) erhoben.

Eine ähnliche Vorgehensweise verfolgt Touaillon auch beim rationalistischen Frauenroman, den sie zunächst in „zwei natürliche Gruppen“, den rationalistischen Gegenwarts- und den rationalistischen Vergangenheitsroman, teilt. Erstgenannter schließe laut Touaillon „unmittelbar an den rationalistischen Männerroman“ an, besitze unter „allen Romanrichtungen des 18. Jahrhunderts [...] die weitaus größte Zahl von Vertreterinnen“" (Touaillon 1919, 233) und widme sich ausschließlich der „Stellung des Menschen innerhalb der bürgerlichen Familie“ (Touaillon 1919, 234). Die einzige Autorin, die sich ernsthaft vom Familienmilieu abgewendet habe, sei Benedicte Naubert gewesen, deren Hauptleistung Touaillon trotz des großen Erfolgs ihres Gegenwartsromans Die Amtmannin von Hohenweiler $(1787)^{70}$ - im Vergangenheitsroman, also in der Ausgestaltung von "Stoffe[n] der Geschichte und Sage“ (Touaillon 1919, 233), sieht. Naubert, deren Autorschaft bis kurz vor ihrem Tod anonym blieb, ${ }^{71}$ war die

69 Schneider: Die ersten Grundsätze der schönen Künste überhaupt, und der schönen Schreibart insbesondere (1790), S. 190; Schmidt: Richardson, Rousseau und Goethe (1875), S. 62.

70 Touaillon zählt den Roman, dessen Handlung Anfang des 18. Jahrhunderts angesiedelt ist, zum Gegenwartsroman; nach neueren Definitionen, nach denen die Romanhandlung des historischen Romans nicht „Selbsterlebtes und Erinnertes“ enthalten dürfe, ist er dem Vergangenheitsroman zuzuordnen. Vgl. u. a. Schabert: Der historische Roman in England und Amerika (1981), S. 4.

71 Erst 1817 nannte Karl Julius Schütz in der Zeitung für die elegante Welt erstmals Nauberts Namen. Dass sich Naubert „zweiunddreißig Jahre hindurch nicht zur 
erste deutschsprachige Schriftstellerin, die sich in ihrer literarischen Produktion mit historischen Stoffen beschäftigte. Die zeitgenössische Geschichtsforschung hatte sich im „Anschluß an Voltaire, Hume und Robertson" von Theologie und Rechtswissenschaft abgelöst und konzentrierte sich seither nicht mehr auf Einzelereignisse und Herrscherschicksale, sondern trachtete nun - ausgehend von der Annahme einer ,inneren Gesetzmäßigkeit des geschichtlichen Entstehens“ -, die „Gesamtentwicklung des ganzen menschlichen Geschlechtes" darzustellen und die „Existenz eines Zeitkolorits und eines Nationalcharakters“ zu postulieren. (Touaillon 1919, 382) Vor diesem Hintergrund habe sich Nauberts Roman an die „einzige damals vorliegende Form des Geschichtsromans, nämlich an den heroisch-galanten Roman" (Touaillon 1919, 382-383) angeschlossen, diesen aber wesentlich verändert und erweitert. Nicht mehr erdichtete historische Szenerien und das Ineinanderweben von Gegenwart und Vergangenheit spielen bei ihr eine Rolle, sondern ein reflektierter Umgang mit historischen Quellen oder, wie Touaillon - Naubert zitierend - betont, das Ansinnen, „die wahre Geschichte nie zu entstellen und sich nur bei Muthmaßungen eigene Dichtungen zu erlauben“. Dementsprechend sieht Touaillon Nauberts Selbstpositionierung als "ganz bewußt zwischen Geschichte und Dichtung“ angelegt: Sie sei „weder als Gelehrte noch völlig als Romanschreiberin" zu sehen; ihre Romane versieht sie mit „gelehrten Anmerkungen, [...] Bezugnahme[n] auf Chroniken und wissenschaftliche Werke“, gleichzeitig habe sie aber auch „das Bedürfnis, die politischen Tatsachen mit menschlichen Schicksalen zu durchsetzen und mit dem Reiz der Abenteuer auszuschmücken“. (Touaillon 1919, 386)

Nauberts „Auffassung des Weltgeschehens“ schätzt Touaillon „in allen wichtigen Punkten [als] rationalistisch" ein: Dazu zählt sie die skeptische Betrachtung historischer Ereignisse und der bisherigen Geschichtsforschung ebenso wie die Geringschätzung von „Sitten und Meinungen, welche mit ihrer eigenen Zeit in Widerspruch stehen". (Touaillon 1919, 388 -389) Vor allem, dass in Nauberts Romanen alle Entwicklungen einer scheinbar natürlichen, kausal erklärbaren Folgerichtigkeit unterliegen, führt Touaillon auf ihre Nähe zur Aufklärung zurück. ${ }^{72}$ Für die Emp-

Urheberschaft ihrer sehr beliebten Romane bekannt[e]“, begründet Touaillon damit, dass „Bescheidenheit [...] der innerste Grundzug ihres Charakters gewesen“ sei. Touaillon: Der deutsche Frauenroman des 18. Jahrhunderts (1919), S. 341.

72 Das Entwicklungsschema von Nauberts Romanen erklärt Touaillon folgendermaßen: „A wird z. B. durch B zu dem Zwecke C erzogen; dieser Zweck C setzt sich aus den Faktoren $c_{1}, c_{2}, c_{3}$ zusammen. Um diese Faktoren und schließlich $C$ 
findsamkeit besitze die Autorin hingegen „kein Organ“ (Touaillon 1919, 404), womit Naubert unter allen deutschen Schriftstellerinnen des 18. Jahrhunderts eine Sonderstellung einnehme. Ganz der unpathetischen Haltung der Aufklärung entsprechend verwehre Naubert empfindsame Naturschilderungen ebenso wie empfindsame Seelenanalysen; stattdessen konzentriere sie sich auf „Tatsachen“ (Touaillon 1919, 405), was aber nicht bedeute, so Touaillon, dass Naubert ein „restloses Verständnis“ (Touaillon 1919, 391) der Welt für möglich halte. Vielmehr bleibe in Nauberts Werken immer ein „unerklärbarer Rest“ (Touaillon 1919, 414), der sie zur „ausgesprochenste[n] Vorläuferin der Romantik“ (Touaillon 1919, 420) mache. Ihre Neuen Volksmärchen der Deutschen (1789-1792) seien „eine der frühesteten Verkündigungen romantischen Geistes“, in denen bereits „vor A.W. Schlegels Theorie und Ludwig Tiecks Praxis“ (Touaillon 1919, 408) Gefühle vom „Standpunkt des Interesses für merkwürdige unerklärliche Regungen“" geschildert werden, der „leichte, selbstironisierende Ton des rationalistischen Erzählers [...] dem Ton der Schwermut" weiche und sowohl der „romantischen Zerrissenheit“ als auch dem „romantische[n] Gefühl der Einheit des Menschen mit der Natur" gehuldigt werde. (Touaillon 1919, 410-411) Auch frühe Motive des Wunderbaren identifiziert Touaillon: So spielen in den Märchen „geheimnisvolle[ ] Träume[ ]“ (Touaillon 1919, 412) und „Dämmerzustände“ ebenso eine Rolle wie „das Grauen in der Natur" und „übernatürliche[ ] Kräfte" (Touaillon 1919, 414-415). Selbst die „Form“ steige, „wie später so häufig in der Romantik“, bis zu einer „Dichtung dritter Potenz“ auf, bestehe also aus „Rahmen, Kernerzählung, Erzählung in der Erzählung, Rahmen“. (Touaillon 1919, 419) Diese bemerkenswert frühe Hinwendung zur Romantik sei laut Touaillon damit zu erklären, dass Naubert - im Unterschied zu den meisten Autoren ihrer Generation $-^{73}$ sich nach rationalistischen Anfängen nicht dem Sturm und Drang und der Empfindsamkeit gewidmet habe, sondern „unter Beibehaltung aufklärerischer Grundlagen unmittelbar zur Romantik" (Touaillon 1919, 421) übergegangen sei.

Nicht zu überschätzende Bedeutung habe Naubert aber auch für die Erneuerung des historischen Romans im 18. Jahrhundert. Der Vergleich mit den zeitgenössischen männlichen Verfassern von Geschichtsromanen

hervorzubringen, müssen die Mittel d, e, f angewendet werden.“ Touaillon: Der deutsche Frauenroman des 18. Jahrhunderts (1919), S. 390 (Anm. 152).

73 Touaillon nennt Johann Wilhelm Ludwig Gleim, Justus Möser, Johann Gottfried Herder, Gottfried August Bürger, Maler Müller, Wilhelm Heinse, Johann Wolfgang Goethe und Johannes Müller. 
lässt Touaillon ein klares Urteil fällen: Christian August Vulpius' Romane seien ihren „gänzlich wesensfremd“ und „nur geeignet, den Geschmack zu verschlechtern“. (Touaillon 1919, 429-430) „[W] aber immer noch tief genug unter Benedicte Naubert" positioniert Touaillon die „einförmig[en] und unkünstlerisch[en]“ Romane von Friedrich Christian Schlenkert und Christian Heinrich Spieß. (Touaillon 1919, 431) Ignaz Aurelius Feßler gesteht sie zwar zu, dass er, wie Naubert, die Vernunft über die Leidenschaft stelle, jedoch könne er mit ihr bezüglich der „Frische und Lebhaftigkeit des Temperaments“, der „Echtheit der Gestalten“ und der Realistik ihres „pessimistische[n] Weltbild[s]" nicht mithalten. (Touaillon 1919, 429)

Mit Veit Weber, der zeitgenössisch und auch in der wissenschaftlichen Forschung die größte Aufmerksamkeit unter allen Verfassern historischer Romane erhalten hatte, verbinde die Autorin zwar dasselbe Stoffgebiet und die Art der Benutzung historischer Quellen, aber in der literarischen Ausgestaltung stünden seine „ungeheure[n] Metaphern“, „geschwollene[n] Reden und abgeschmackte[n] Vergleiche[ ] "ihrer „einfachen, natürlichen [...] Sprache" gegenüber. (Touaillon 1919, 427) ${ }^{74}$ So sei es nicht Weber, sondern Naubert gewesen, die im 18. Jahrhundert „den Geschichtsroman recht eigentlich in Schwung gebrach" " (Touaillon 1919, 434) habe; auch wenn sie in der Literaturhistoriographie „gar nicht“ oder „nicht ihrer Bedeutung entsprechend" gewürdigt werde. (Touaillon 1919, 440)

Dass Naubert eine derartige Höhe literarischen Schaffens überhaupt erreichen konnte, erklärt Touaillon damit, dass sich bei ihr „[v]iel weniger deutlich als bei den anderen Schriftstellerinnen dieser Zeit [...] die Geschlechtszugehörigkeit" zeige. So deute eigentlich, wie auch während der Zeit ihrer Anonymität vermutet, vieles auf einen Mann als Verfasser hin: die „Freude an der Tat", das „Ausweichen vor der Empfindung“, die „Bevorzugung männlicher Helden“, die „Ablehnung familiärer Stoffe“ ebenso wie die „Bestimmtheit und Energie des Tones“. Dazu habe „zu ihrem Besten und dem des deutschen Romans", wie Touaillon betont, nicht nur die „Erziehung durch Männerhand und Männergeist“, sondern

74 Den Vergleich mit Weber nimmt Touaillon auch zum Anlass, das Werturteil des Leipziger Professors für Germanistik, Albert Köster, zurückzuweisen: Dieser hatte 1897 im Anzeiger für deutsches Altertum behauptet, dass Webers Werke die „Echtheit des Kolorits“ auszeichne, Naubert aber „mit tausend Anachronismen und Verstößen gegen Stil und Empfindungsweise der älteren Zeit" erzähle, was, so Touaillon, nichts anderes heißt, als „ihn zu einer ungerechtfertigten Höhe hinaufzuschrauben, ihr aber schweres Unrecht zu tun“. Touaillon: Der deutsche Frauenroman des 18. Jahrhunderts (1919), S. 428. 
auch der „schon angeborene[ ] männliche[ ] Keim in der Seele Benedicte Nauberts" beigetragen. (Touaillon 1919, 435-436)

Den Abschnitt über den klassizistischen Frauenroman eröffnet Touaillon mit Caroline von Wolzogen, die sie „[u]nter den deutschen Frauen des 18. Jahrhunderts“ zu „eine[r] der Begabtesten“ zählt. (Touaillon 1919, 451) Wolzogens Hinwendung zu Idealen der klassischen Antike, zu Maß, Harmonie, Reinheit und Erhabenheit, erklärt Touaillon aus dem Charakter der Autorin. So sei Wolzogen ein „echt moderner nervöser Mensch“ gewesen, der „das mangelnde Gleichgewicht [seines] Herzens" durch die Erschaffung „eine[r] zweite[n] Welt" auszugleichen gesucht habe, „weil ihr die erste zu traurig und zu gewöhnlich" erschien:

Sie sucht daher die Harmonie, welche ihrem eigenen Wesen fehlt, aus fremder Größe zu schöpfen: Kant stärkt sie, Herder versöhnt sie mit dem Leben, Homer und Goethe schaffen ihr eine höhere und freundlichere Welt. Größe zu lieben, ist ihre Seeligkeit, mag es nun Menschengröße oder Größe einer Idee sein. (Touaillon 1919, 452-453)

Wolzogens „allzu verletzliches Herz will die Welt nicht sehen, wie sie ist“, weshalb ihre Romane nicht „der lebendige Zusammenhang mit einer blühenden Wirklichkeit" auszeichne, viel eher wirken sie, so Touaillon, „wie ideale Landschaften, erhaben und unwirklich“. (Touaillon 1919, 453) Ihre Bildung verdanke Wolzogen den intellektuellen Größen ihrer Gegenwart: zum einem ihrem Schwager Friedrich Schiller, der ihr "die großen Geschichtsschreiber des Altertums“, „die griechischen Tragiker, Homer und die griechische Komödie" näherbrachte, zum anderen Wilhelm von Humboldt, durch den sie Plato und Euripides kennenlernte, aber auch Goethe, der sie mit seinem „Atem erfüllt" habe. (Touaillon 1919, 455)

Ihr erstes größeres Werk, der Roman Agnes von Lilien, der 1793 entstand, dessen erster Teil 1796 und 1797 in Schillers Zeitschrift Die Horen erschien und der 1798 durch Schillers Vermittlung bei Unger in Berlin auch als Buchausgabe publiziert wurde, habe laut Touaillon in seiner Technik den „Zusammenhang mit dem älteren Romane noch nicht ganz abgestreift“, sei aber inhaltlich eindeutig dem „neue[n] Typus“ des klassizistischen Romans zuzurechnen. Dabei bilde Agnes von Lilien „[d]eutlicher als die meisten anderen Werke jener Zeit“ ein "Zwischenglied zwischen Aufklärung und Romantik“: Das Leben sei der Autorin nicht mehr selbstverständlich und klar und noch nicht geheimnisvoll erschienen, sondern „als eine Aufgabe, die in Schönheit gelöst werden“ müsse. Auch habe sie bereits die „Erkenntnis des Gegensatzes zwischen Herz und Welt“ besessen, der aber nicht wie in der Romantik „lebenszerstörend“, sondern 
nur als „sanfte[r] Schmerz“ auf sie wirkte. (Touaillon 1919, 463-464) Der Natur räumte Wolzogen eine wesentlich größere Rolle ein als der Rationalismus, sie begann sie zu beleben, aber nicht mit romantisch-erschreckenden, sondern mit „freundlichen Gestalten“. Insgesamt war ihr die „Harmonie [...] das oberste Gesetz in allen Verhältnissen“, was sich nicht zuletzt in Wolzogens „starke[m] Gefühl für die Form und [ihre] Vorliebe für edle Bilder", für die ihr die Antike das Schönheitsideal lieferte, zeige. (Touaillon 1919, 464-465) Der "ganze künstlerische Umwandlungsprozeß, den die Dichterin mit der Wirklichkeit vornimmt", sei „echt klassizistisch“: So interessierte sie nicht das Alltägliche, Äußere des Lebens, sondern dessen „inneres rätselhaftes Wesen“, das sie durch Abstraktionsprozesse, philosophische Begriffe und den „Grundsatz der idealen Ferne“ zu fassen suchte. Dadurch sei es Wolzogen gelungen, nicht nur eine überaus symbolische Welt zu erschaffen, sondern den Dingen des Lebens stets auch einen höheren Sinn zu verleihen. (Touaillon 1919, 466-467)

Hinsichtlich des ästhetischen und ethischen Konzepts des Romans sei, so Touaillon, Schillers Einfluss nicht zu übersehen; überhaupt mute Agnes von Lilien „wie ein Beispiel zu seiner Theorie“ an. Schillers Überlegungen zur Aufgabe der Kunst als Veranschaulichung des Schönen und Erhabenen zeigen sich laut Touaillon vor allem in den Figuren Agnes, Nordheim und Alban, die Wolzogen als „schöne und erhabene Charaktere in ihren schönen und erhabenen Handlungen“ zeichnete. Seine doppelte Wirkungsbestimmung als Erholung und Veredelung habe die Autorin insofern übernommen, als „der sittliche und ästhetische Kern ihres Romans der Veredlung, seine Gestaltung romanhafter Schicksale der Erholungen“" diene. Ebenso führt Touaillon die Konflikte des Romans auf „den Kampf der sittlichen Natur des Menschen mit dem Naturgesetz im Schillerschen Sinne“ zurück, und das, „was Schiller als Begriff der Tugend hinstellt", sei dadurch vertreten, dass die Helden des Romans die Fähigkeit besitzen, „aus jeder Begebenheit Vergnügen zu schöpfen und jeden Schmerz in die Vollkommenheit des Universums aufzulösen“. Der Anlehnung an Schiller sei die „künstlerische Reinheit ihres Romans“ zu verdanken, der nicht „wie ein Ausschnitt aus dem Leben, sondern wie ein geläuterter Extrakt des Lebens“ wirke, also „einer Kunsttheorie zuliebe“ ein spannungsfreies „Ideal von Leben und Welt" darstelle. (Touaillon 1919, 470-471)

In der Geschlechterfrage stehe Wolzogen, wie auch sonst, „auf dem Boden des Klassizismus" und der "Schiller-Humboldtschen Auffassung", nach der sowohl Mann als auch Frau erst durch die Liebe zu ganzen Menschen werden. (Touaillon 1919, 472-473) In seiner Rezension des Romans huldigte Wilhelm von Humboldt, den Touaillon hier zitiert, der 
„Klarheit, Wahrheit und Freiheit des Denkens und des Empfindens“"von Agnes von Lilien, dem „Gleichgewicht ihrer Seele“ und ihrem „Fernsein von jeder Verwirrung" und hebt - ganz dem klassizistischen Frauenideal entsprechend - hervor, dass die Heldin nicht der „abgesonderte[n] phantasielose[n] Beschäftigung des Verstandes", sondern dem Gefühl den Vorzug gebe. Tatsächlich verkörpere die Heldin, so Touaillon, das Ideal der „angeborene[n] Orientierung der Frau in der moralischen Welt" und sei gleichberechtigt „neben Gretchen, Klärchen, Marianne und andere Ge-

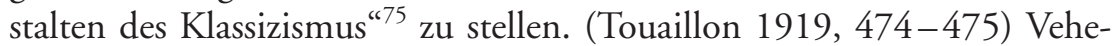
ment widerspricht Touaillon derjenigen Forschungsliteratur, die Agnes von Lilien eine „Selbstbiographie in Romanform“"nennt. (Touaillon 1919, 478) In Wirklichkeit sei die Romanhandlung aus Motiven der älteren Romantradition zusammengesetzt und dort, wo tatsächlich Ähnlichkeiten mit Wolzogens Leben auszumachen seien, werden diese, wie es der „Kunstatmosphäre und Kunstauffassung eines klassizistischen Romans" entspricht, in eine ,ideale Ferne“ gerückt, sodass „von einem sklavischen Anschluß [an ihre Biographie, E.G.] keine Rede" sein könne. (Touaillon 1919, 481)

Seinen großen Erfolg verdanke der ursprünglich anonym erschienene Roman auch nicht einer möglichen autobiographischen Färbung, vielmehr sei dieser zunächst literarischen Größen wie Friedrich Schiller, Johann Wolfgang von Goethe und Friedrich Heinrich Jacobi zugeschrieben und „allgemein als ein Werk empfunden worden [...], das von der Linie des Gewöhnlichen abwich“. (Touaillon 1919, 484) Neben Goethe und Wilhelm Humboldt seien u. a. auch von Caroline Schelling und Charlotte von Stein bewundernde Zeugnisse über den Roman erhalten; Christian Gottfried Körner bezeichnete Agnes von Lilien als die „Arbeit eines vorzüglichen Kopfes “"76 und Heribert Dalberg meinte „Schillers Meisterhand zu erkennen "77. Nur die Romantiker schienen mit Wolzogens Roman nicht richtig warm geworden zu sein: Friedrich Schlegel revidierte sein anfänglich positives Urteil und schrieb den Erfolg des Romans „dem Cliquenwesen und der geringen Kultur des Adels ${ }^{\text {c78 }} \mathrm{zu}$, was Touaillon mit

75 Gemeint sind Goethes Frauenfiguren in Faust, Egmont und Die Geschwister.

76 Dieses Urteil Körners zitiert Touaillon nach Schiller/Cotta: Briefwechsel (1876). Touaillon irrt jedoch bei der Seitenangabe, tatsächlich findet sich das Zitat nicht, wie bei Touaillon vermerkt, auf S. 6, sondern auf S. 193.

77 Diese Einschätzung Dalbergs findet sich, wie Touaillon korrekt vermerkt, in dessen Brief an Friedrich Schiller vom 29. Jänner 1797. Urlichs (Hg.): Briefe an Schiller (1877), S. 277.

78 Touaillon fasst mit diesen Worten Friedrich Schlegels Kritik an Wolzogens Roman zusammen, die dieser in einem Brief an August Wilhelm Schlegel vom 28. und 
Schlegels Abneigung gegen Schiller begründet wissen will. (Touaillon 1919, 484-485) Und auch Clemens Brentano, der bekanntermaßen „von Frauendichtung überhaupt nichts hielt" (Touaillon 1919, 486), verspottete in seiner 1800 publizierten Literatursatire Gustav Wasa Wolzogens Buch. Diese Ablehnung der Romantiker beruhte, so Touaillon, jedoch auf Gegenseitigkeit; so habe Wolzogen Zeit ihres Lebens darauf geachtet, „den neuen [romantischen, E.G.] Romanen ,voll zerrissener und verkehrter Menschheit“" ihren „,einfachen Rechts- und Liebessinn“" gegenüberzustellen, um - ganz im Sinne des Klassizismus - mit ihren Werken „das Gute zu befördern“". (Touaillon 1919, 500)

Im letzten Abschnitt ihrer großen Studie beschäftigt sich Touaillon schließlich mit romantischen Elementen im deutschen Frauenroman, wobei sie sowohl auf Dorothea Schlegel als auch auf die von ihr als Entdeckung porträtierte Autorin Karloine Auguste Fischer eingeht. Dorothea Schlegel werde laut Touaillon als „einzige offizielle Vertreterin des romantischen Frauenromans" gehandelt, sei aber ihrem Wesen nach eigentlich von gänzlich „unromantische[r] Natur" gewesen. (Touaillon 1919, 557) Vielmehr habe sie, so Touaillon, Zeit ihres Lebens mehr von den rationalistischen Ansichten ihres Vaters Moses Mendelssohn als von den romantischen Ideen ihres zweiten Mannes Friedrich Schlegel gehalten und sei nur aufgrund einer bemerkenswerten „Unselbständigkeit im Denken“ und einer „bedingungslosen geistigen Hingabe an den geliebten Mann und seinen Kreis" der Romantik zuzuordnen. So würden sich Schlegels literarische Werke vor allem als Zeugnisse eines "künstlerischen Zwiespalt[s]“ lesen lassen; das 1801 publizierte Romanfragment Florentin zeige, dass Dorothea Schlegel dort, wo sie Gedanken und Tendenzen aussprach, romantischen Konzepten folgte, bei der eigentlich künstlerischen Arbeit, der „Schöpfung von Gestalten“ und der „Verkörperung von Empfindungen“ aber die Vernunft die Oberhand gewann. (Touaillon 1919, 559-560) Überhaupt lasse sich in dem Roman, so Touaillon, „keine Spur von dem überwältigenden Tönerauschen, der erschütternden Lebensklage, dem hinreißenden Naturgefühl der Romantik“ finden; er wirke viel eher „wie die Probe eines geschickten Rechners, der die romantischen Regeln mit dem Verstande aufnahm“ (Touaillon 1919, 572), weshalb „von einer selbständigen Bedeutung Dorotheas gar keine Rede sein" könne und sie ihre im Vergleich zu anderen Autorinnen große Beachtung durch die

29. Dezember 1797 äußerte. Der Brief war Touaillon zugänglich bei Walzel (Hg.): Friedrich Schlegels Briefe an seinen Bruder August Wilhelm (1890), S. 337-343. 
Forschung „nur ihren persönlichen Beziehungen zur romantischen Schule“ (Touaillon 1919, 577) verdanke.

Ganz anders fällt Touaillons Urteil über Karoline Auguste Fischer aus, der weder zu ihren Lebzeiten noch in der Literaturgeschichte nennenswerte Beachtung geschenkt wurde. Zu Unrecht, wie Touaillon findet, da die Autorin nicht nur „durch ihre Eigenart, durch die Kraft ihrer Empfindung und Darstellung alle anderen deutschen Frauen des 18. Jahrhunderts weit" übertreffe (Touaillon 1919, 578), sondern gleichzeitig auch eine „glutvolle Vorkämpferin der neuen Frauenrechte" gewesen sei, wie nicht nur ihr literarisches Oeuvre, sondern auch ihre feministische Abhandlung Über die Weiber (1813) zeige. (Touaillon 1919, 582) Bereits Fischers erster, 1801 in Leipzig publizierter Roman Gustavs Verirrungen zeichne sich, so Touaillon, durch einen „völlig neuen Geist“ aus, dem die „Welt der Tugend“ genauso fern liege wie die „Welt der sanften Gefühle“. Vielmehr falle die „Kühnheit des Grundmotivs" auf, in dem es nicht wie bisher um die Beschreibung eines fertigen oder die Vorgabe eines idealen Zustandes gehe, sondern um die Art und Weise, wie ein Mensch zu dem wird, was er ist. In einer Entwicklungs- und Bildungsgeschichte wird der Held Gustav von seiner Kindheit bis zu seinem Tod - und darüber hinaus - begleitet. Dabei wird selbst die „kühne Schilderung der Leidenschaft und Sinnlichkeit“ nicht ausgespart, was, wie Touaillon betont, „bei einer Frau an der Wende des 18. Jahrhunderts noch ein unerhörtes Wagnis“ gewesen sei. (Touaillon 1919, 584-585) Darüber hinaus zeichne sich der - durch den Bericht des Protagonisten und dessen Freundes - in zweifacher Ich-Perspektive verfasste Roman durch die Knappheit der Darstellung, das rasche Tempo, die häufigen Dialoge und die gewandte Sprache aus.

Fischers zweiter Roman Die Honigmonathe (1802) nimmt seinen Ausgang in einem vehementen Protest gegen Karoline von Wobesers 1795 erschienenen Erfolgsroman Elisa, oder das Weib wie es seyn sollte, in dem die bedingungslose Unterordnung der Frau unter den Mann gefordert wird. Bemerkenswert und beispiellos findet Touaillon die Konzentration des Romans auf „innere Schicksale“ und den „Nutzen der Leidenschaften“, die, so Touaillon, zum ersten Mal im deutschen Frauenroman nicht nur die ,sanften' Gefühle verdrängen, sondern ohne die sich vor allem auch kein moralisches Bewusstsein entwickeln könne. (Touaillon 1919, 588) Damit verabschiede Fischer ein Frauenideal, ,in welchem Weichheit gleich Tugend, Härte gleich Laster" gewesen sei, und stelle stattdessen ein "gesundes Gleichgewicht zwischen Egoismus und Altruismus" her. (Touaillon 1919, 591-592) Auch habe Fischers Sprache nichts von der „Weitschweifigkeit und Schwerfälligkeit" der Literatur des 18. Jahrhunderts, sondern zeichne 
sich durch „Witz und Ironie“, „bewunderungswürdige Prägnanz“ und einen „vollendete[n] Satzrhythmus“ aus. (Touaillon 1919, 593)

Fragt man nach der literaturgeschichtlichen Einordnung von Fischers Romanen, so können laut Touaillon einzelne Anklänge an die Aufklärung („die Art der sozialen Betrachtung"), den Rationalismus („die logische Schärfe [...], die kluge Beschränkung ihrer Handlung") und den Klassizismus (das Bedürfnis einzelner Figuren nach innerer Harmonie) gefunden werden. (Touaillon 1919, 603) Insgesamt weise das Werk der Autorin aber in eine andere Richtung, nämlich in die Jean-Jacques Rousseaus. Von Rousseau habe Fischer die große Bedeutung des Gefühls gegenüber der Vernunft, die „Ablehnung des Mitleids“, die Darstellung der Leidenschaft und der Sinnlichkeit sowie das „Eintreten in medias res“, die „Sicherheit der Exposition“ und die „glutvolle, hinreißende Sprache“ übernommen, die sie gleichzeitig auch mit dem Sturm und Drang in Verbindung bringe. (Touaillon 1919, 604-605) Besonders ausgeprägte Übereinstimmung finde sich aber mit der Romantik, mit der Fischer die Ablehnung logischgesicherter Erklärungen, die Bedeutung ungewisser Vorgänge, die schwärmerisch-schwermütige Grundstimmung und die als unbegreifbar und schwankend dargestellten Menschen, denen das Unbewusste näher als das Bewusste sei, verbinde. Die Natur sei bei ihr, wie bei den Romantikern, unergründlich, unbarmherzig und übermächtig zugleich und trotzdem die einzige „Erleichterung im tiefsten Schmerz“ (Touaillon 1919, 608). Ebenso teile sie mit den Romantikern die freie und unbürgerliche Auffassung zwischenmenschlicher Beziehungen sowie die große Bedeutung, die sie der Kunst als Lebensgrundlage beigemessen habe. Doch auch, wenn Fischer alle literarischen Strömungen ihrer Zeit in sich aufgenommen habe und dichterisch zu gestalten im Stande gewesen sei, so falle vor allem ihre „selbständige[ ] künstlerische[ ] Kraft" ins Auge, die ihr erlaubt habe, nicht nur weit über die Romantik, sondern überhaupt über ihre Gegenwart hinauszugelangen. Touaillon sieht in Fischer eine entschiedene Vorläuferin des modernen deutschen Romans, betont ihre unerschrocken geäußerte demokratische Gesinnung, die Komplexität ihrer Figuren, ihre „eugenetischen Forderungen" (Touaillon 1919, 610-611) und vergleicht sie mit Jaques Dalcroze und Gerhart Hauptmann. (Touaillon 1919, 614)

Fischers Ansichten in der Frauen- bzw. Geschlechterfrage schätzt Touaillon als ausgesprochen fortschrittlich ein; so sei sie die erste deutsche Schriftstellerin gewesen, „die es wagte, Ansichten über Mann und Frau auszusprechen und künstlerisch zu verkörpern, welche nicht weniger revolutionär als die romantischen Ansichten waren" (Touaillon 1919, 622). Dem Mann trete sie durchweg in „Feindschaft“ (Touaillon 1919, 614) 
gegenüber; sein Machtanspruch und seine Besitzansprüche an die Frau werden immer, wenn zumeist auch ironisch, als unberechtigt dargestellt; hervorgehoben werde dafür der selbständige und souveräne Status der Frauenfiguren. Wie die Romantiker habe Fischer, so Touaillon weiter, die Ehe reformiert und leichter lösbar sehen wollen; in ihrem Roman Die Honigmonathe habe sie deshalb ein Ehekonzept entwickelt, das dem von Goethes Wahlverwandtschaften ähnlich sei: In diesem Konzept soll die Ehe nur auf Zeit geschlossen werden und alle fünf Jahre erneuert oder geschieden werden, womit, wie Touaillon betont, „nicht etwa einer Lockerung der ehelichen Bande das Wort geredet“, sondern nur der „Verödung und Versumpfung des Alltags" Einhalt geboten werde. (Touaillon 1919, 617)

Mit ihren Ansichten über die Frauenfrage habe Fischer Pionierarbeit geleistet. Wenn überhaupt von „Vorläufer[n]“ gesprochen werden könne, dann seien diese Touaillon zufolge Mary Wollstonecrafts A Vindication of the Rights of Woman (1792) und Theodor Gottlieb von Hippels Über die bürgerliche Verbesserung der Weiber (1792). Mit der Britin verbinde Fischer nämlich die Forderung nach der umfassenden Aufklärung von Frauen über sexuelle Fragen, nach ihrer Selbstbestimmung sowie „nach Entfaltung der weiblichen Persönlichkeit [...] zu bewußter Würde“. Im Vergleich mit Hippel wiederum zeige sich eine auffallende Ähnlichkeit der Rhetorik und der Anschauungen. In einer scharfen „Polemik gegen den Mann“ werde von beiden ,in zugespitzten Antithesen“, mit „bittere[m] Hohn“ und einer „Sprache der Überlegenheit" die „passive Existenz der Weiber" verurteilt und davon ausgegangen, dass die Unterdrückung von Frauen dazu führe, dass „die Hälfte der menschlichen Kräfte ungekannt, ungeschätzt und ungebraucht schlummere". (Touaillon 1919, 622-623) Trotz dieser insgesamt die Gleichberechtigung der Geschlechter postulierenden Ansichten von Fischer seien, wie Touaillon bemerkt, in der Gestaltung ihrer Frauenfiguren teilweise auch widersprüchliche Tendenzen zu bemerken. So folge sie zwar dort, wo sie das neue Frauenideal darstelle, Wilhelm von Humboldts Auffassung, dass „über dem Geschlechtscharakter noch ein reiner Menschheitscharakter" stehe, und entwerfe daher wie er den „Typus des dritten Geschlechts". (Touaillon 1919, 625-626) Dieser sei bei Fischer aber zölibatär gestaltet, also der "Geschlechtsliebe“ gänzlich entzogen. Touaillon interpretiert diese Auslegung des neuen Frauenbilds durch Fischer als unnötige Einschränkung, die daraus resultiere, dass der Autorin ein Verhältnis zwischen Mann und Frau unter gleichberechtigten Bedingungen noch unmöglich erschienen und ihr deshalb „der Ausweg, [...] Geschlechtlichkeit und Unabhängigkeit von der Herrschaft des Mannes zu 
vereinen“, verborgen geblieben sei. Da aber Fischers wesentliche künstlerische Verdienste „auf allgemein menschlichem Gebiete“ zu finden seien, habe die Autorin, so Touaillon, „trotz dieses Irrweges nicht an Wirkung eingebüßt“. (Touaillon 1919, 629)

In der Zusammenfassung ihrer Studie streicht Touaillon zunächst die Ähnlichkeiten zwischen den von Frauen und den von Männern verfassten Romanen heraus: Sowohl Motivik, Gestaltung, Zeit und Ort als auch Handlung, Weltbild, Tendenz und Ton des Frauenromans entsprächen denen des Männerromans, was zum einen damit zu erklären sei, dass Autorinnen „in ihrem ganzen geistigen Leben von vornherein unter dem überwiegenden Einfluß des Mannes" gestanden seien, zum anderen aber auch genealogische Ursachen habe, ein „ständiger Austausch geistiger Merkmale zwischen Mann und Frau" also deshalb stattfinde, weil, wie Touaillon betont, „die Anlagen sich häufig kreuzweise vererben“. (Touaillon 1919, 634-625) Trotzdem identifiziert Touaillon auch eine Reihe von Unterschieden: So hätten sich Schriftstellerinnen stärker auf Stoffe konzentriert, die ihrem unmittelbaren Lebensumfeld nahe standen, sich eher von erotischen Szenen ferngehalten und pragmatische Lösungen in zwischenmenschlichen Fragen bevorzugt. Sie hätten also, wie Touaillon sich ausdrückt, eine „Realpolitik den Gefühlen gegenüber“ betrieben. (Touaillon 1919, 637) Darüber hinaus seien Frauen, die im 18. und frühen 19. Jahrhundert als Autorinnen hervortraten, ganz im Gegensatz zu den in Literaturgeschichten häufig verbreiteten Vorurteilen und im Unterschied zu ihren männlichen Autoren, zumeist durch eine „Doppeltätigkeit“ belastet gewesen. Diese habe, wie Touaillon hervorhebt, nicht nur aus ihrer schriftstellerischen Arbeit, sondern vor allem auch aus der "tadellose[n] Erfüllung ihrer familiären Pflichten“ bestanden. (Touaillon 1919, 638)

Die Ansicht, die deutschen Schriftstellerinnen des 18. Jahrhunderts wären zum größten Teil verstiegene und überspannte Frauen und unbefriedigte alte Mädchen gewesen, welche ein erträumtes Leben dem wirklichen vorgezogen und dabei ihre Pflichten vernachlässigt hätten, ist nichts als ein Märchen. (Touaillon 1919, 637)

Im Vergleich zu den männlichen Autoren hätten sich Schriftstellerinnen außerdem häufiger mit sozialen und ökonomischen Belangen auseinandergesetzt, vehementer gewaltsame Konflikte und Kriege abgelehnt und eher „zum erzieherlichen Wirken“ geneigt. (Touaillon 1919, 642) Gleichzeitig gebe es in den Frauenromanen, so Touaillon, nur selten philosophische, natur- oder kunsttheoretische Erörterungen; eine „Spur jenes heißen Ringens um die Weltgeheimnisse, [...] wie es im 18. Jahr- 
hundert bei den Männern geradezu das Merkmal jedes großen Geistes“ gewesen sei, fehle überhaupt ganz. (Touaillon 1919, 640)

Der Vorstellung, dass diese „Verschiedenheiten der Werke“ auf „Verschiedenheiten der männlichen und weiblichen Natur" beruhen könnten, widerspricht Touaillon trotzdem mit Nachdruck. Vielmehr seien sie einzig und allein mit „den verschiedenen Lebensverhältnissen“ und „den Anschauungen des 18. Jahrhunderts über das Verhältnis der Geschlechter" zu erklären. (Touaillon 1919, 643) Unzureichender Unterricht, das Fernhalten von öffentlichen Positionen, die Festschreibung auf das familiäre Umfeld, die engen Tugendvorstellungen hätten nicht nur dazu geführt, dass Frauen erst im Durchschnitt mit Mitte dreißig, also viel später als Männer, zu schreiben begannen, sondern gleichzeitig auch die Grenzen der Handlung, die Technik, die Sprache und den Ton der Romane bestimmt. Die gebräuchliche „Anekdote von der Veröffentlichung eines Werkes ohne Vorwissen der Verfasserin" und die vorherrschende erzieherische Tendenz der Romane seien wiederum darauf zurückzuführen, dass Öffentlichkeit und literarisches Schaffen von Frauen nur dann gebilligt worden sei, wenn ein klar erkennbarer, von Männern abgesegneter Nutzen damit verbunden war. (Touaillon 1919, 645) Daraus lasse sich auch die starke Beteiligung von Schriftstellerinnen an Romanen der Aufklärung erklären, die durch das familiäre Setting und die pädagogische Ausrichtung den Lebensumständen der Frauen entgegengekommen seien, während der Genieroman des Sturm und Drang nicht nur dem männlichen Frauenideal widersprochen, sondern auch durch seine Entstehung im akademischen, universitären Umfeld Frauen von vornherein ausgeschlossen habe. Die geringe Beteiligung von Schriftstellerinnen an der Romantik erklärt Touaillon wiederum mit der darin postulierten Auflösung familiärer und ehelicher Verbindungen; die wenigen Autorinnen des Klassizismus mit dessen Anspruch eines „hohen, in Bildung umgesetzten Wissens“. Einzig die Empfindsamkeit habe es als „Revolution der Schwachen“ den Frauen ermöglicht, über ihre Unzufriedenheit zu klagen, ohne gleichzeitig zu - als unweiblich empfundener - Empörung oder gar zur Tat schreiten zu müssen. (Touaillon 1919, 648-649)

Ihre Studie beendet Touaillon mit einer kurzen und - im Vergleich zu ihren bis dahin überwiegend historisch fundierten Erörterungen - auffällig spekulativen Diskussion einer Frage, die zu Beginn des 20. Jahrhunderts äußerst populär war und zumeist polemisch verhandelt wurde. Nämlich, ob der deutsche Roman durch den Eintritt von Frauen eine „Bereicherung oder Verarmung" erfahren habe. Auffällig sei laut Touaillon zunächst, dass das „Überhandnehmen der weiblichen Schriftstellerei“ dazu geführt habe, 
dass die Thematik der Liebe und Ehe alle anderen zwischenmenschlichen Beziehungen in den Hintergrund gerückt habe und bis zum Beginn des 20. Jahrhunderts nahezu kein Roman ohne Liebesgeschichte auszukommen wagte. (Touaillon 1919, 649) Damit haben, so Touaillon weiter, Autorinnen „dem Dilettantismus und der Seichtigkeit ein bequemes Feld bereitet" (Touaillon 1919, 651). Glücklicherweise sei es dem Roman als Gattung aber gelungen, „um seine Geltung als Kunstwerk zu ringen“ und „sich innerlich mehr und mehr zu reinigen“. Gleichzeitig habe der deutsche Roman den Schriftstellerinnen aber auch eine beachtliche Anzahl an Vorteilen zu verdanken. Neben der „sittliche[n] Reinigung“ nennt Touaillon die Mäßigung in sexuellen Fragen, die Eindämmung der Leidenschaft und die Entwicklung eines sozialen Empfindens, aber auch die Verfeinerung psychologischer Betrachtungsweisen, die allesamt zur „Verinnerlichung des deutschen Romans" beigetragen hätten. (Touaillon 1919, 652-653) Damit reiche der deutsche Frauenroman, wie Touaillon in einem Zugeständnis an die zeitgenössische Auffassung schreibt, „Zwar nicht an die vollkommensten Schöpfungen des Männerromans" im 18. Jahrhundert heran; für die Literaturgeschichtsschreibung von Interesse sei er aber trotzdem, da „den Schäden, welche er mit sich brachte, eine Reihe von Vorteilen gegenübersteht", sodass er „eine wichtige Sendung erfüllt [habe], die aus der Geschichte des Romans nicht mehr weggedacht werden kann“". (Touaillon 1919, 654-655)

\section{II.3. Kanon und Geschlecht}

Als Christine Touaillon 1919 ihre Habilitationsschrift über den deutschen Frauenroman des 18. Jahrhunderts veröffentlichte, war die Erforschung von Literatur von Frauen hauptsächlich im außerakademischen Bereich zu finden. Zwar beschäftigte sich die Germanistik traditionell viel mit Frauen, doch nur selten mit Frauen als Produzentinnen von Literatur. Viel häufiger dienten sie als Musen und Imaginationen der ,großen ' Dichter. ${ }^{79}$ Die Rede vom ,Weiblichen' wurde als Bündel von Eigenschaften verstanden, das dazu diente, Theorien und methodische Ansätze als nicht konstruiert, sondern als natürlich begründet erscheinen zu lassen. Eines der bekanntesten und einflussreichsten Unterfangen in dieser Hinsicht ist das literaturhistorische Epochenschema Wilhelm Scherers. Um seine Geschichte der

79 Vgl. dazu die nach wie vor grundlegende Studie von Bovenschen: Die imaginierte Weiblichkeit (1979). 
Deutschen Litteratur (1883-1888) zu systematisieren, entwickelte Scherer eine Wellentheorie, anhand der er die drei von ihm angenommenen Blüteperioden um 600, 1200 und 1800 und die zwei Tiefpunkte im 10. und 16. Jahrhundert zu erklären versuchte. In einer „Kopplung von Kausalannahmen und Geschlechtscharakter " ${ }^{\text {"80 }}$ differenzierte Scherer dabei zwischen ,männischen' und ,frauenhaften' Epochen, wobei die ,frauenhaften' aufgrund ihres toleranten und kunstsinnigen Charakters die jeweils literarisch produktiveren und wertvolleren seien. ${ }^{81}$ Den höchsten literarischen Gipfel einer, frauenhaften 'Epoche bildete die deutsche Klassik, allen voran Johann Wolfgang Goethe, mit dessen Tod Scherer seine Literaturgeschichte auch enden lässt. Frauen selbst haben an diesen Blüteperioden keinen produktiven Anteil, ihr, Geschlechtscharakter'verleiht ihnen bloß die attributive Bestimmung.

Ein ganz anderes Bild zeichnen die populären zeitgenössischen Literaturgeschichten. Die beliebtesten und meistgelesenen unter ihnen, die bis zum Beginn des 20. Jahrhunderts häufig in einer nicht enden wollenden Auflagenzahl erschienen, beschäftigen sich ausführlich mit Schriftstellerinnen. So Julian Schmidts Geschichte der deutschen Literatur im 19. Jahrhundert (1853), Rudolf Gottschalls Die deutsche Nationalliteratur in der ersten Hälfte des neunzehnten Jahrhunderts (1855), Robert Prutz' Die deutsche Literatur der Gegenwart (1859) und Ludwig Salomons Geschichte der deutschen Nationallitteratur des neunzehnten Jahrhunderts (1881), um nur einige wenige zu nennen. ${ }^{82}$ Darüber hinaus erschienen in den $1880 \mathrm{er}$ und 1890er Jahren drei Literaturlexika, die ausschließlich Autorinnen verzeichnen: Heinrich Groß' dreibändiges Werk über Deutsche Dichterinen und Schriftstellerinen in Wort und Bild (1885), Marianne Niggs Biographien der österreichischen Dichterinnen und Schriftstellerinnen (1893) und Sophie Patakys Lexikon deutscher Frauen der Feder (1898). Wenn man bedenkt, dass ein derartiges Unterfangen erst wieder fast hundert Jahre später rea-

80 Fohrmann: Das Projekt der deutschen Literaturgeschichte (1989), S. 222.

$81 \mathrm{Zu}$ den Bezeichnungen ,männisch' und ,frauenhaft ${ }^{`}$ vgl. Scherer: Geschichte der deutschen Dichtung im elften und zwölften Jahrhundert (1875). - Zu Scherers literaturgeschichtlicher Konzeption vgl. Müller: Wilhelm Scherer (2000); Michler: An den Siegeswagen gefesselt (1996); Höppner: Das „Ererbte, Erlebte und Erlernte“ im Werk Wilhelm Scherers (1993).

82 Für eine vollständige Auflistung vgl. Fritsch-Rößler: Bibliographie der deutschen Literaturgeschichten (1994); Schumann: Bibliographie zur deutschen Literaturgeschichtsschreibung (1994). 
lisiert werden sollte, ${ }^{83}$ ist die große Aufmerksamkeit, die Schriftstellerinnen am Ende des 19. Jahrhunderts zuteilwurde, durchaus bemerkenswert. Weniger bemerkenswert erscheint sie jedoch, wenn man den Status der Autoren und damit den Institutionalisierungsgrad von Literaturgeschichten betrachtet: Keiner der genannten Verfasser hatte eine nennenswerte akademische Position inne. Einzig Robert Prutz bekleidete ab 1849 kurzfristig eine Professur für Literaturgeschichte in Halle, gab diese aber aufgrund eines gegen ihn angestrengten Disziplinarverfahrens nach wenigen Jahren wieder auf. Julian Schmidt und Rudolf Gottschall gehörten überhaupt nicht dem Kreis der Universitätslehrer an, sondern sahen sich als Publizisten und standen damit im Zentrum der literarischen Öffentlichkeit. Dementsprechend verstanden sie ihre Tätigkeit auch nicht als Vertretung eines Fachs, sondern als eine öffentliche Aufgabe, als Dialog mit dem breiten Publikum. ${ }^{84}$

Die „Einheit von Literaturgeschichte und Literaturkritik ${ }^{\text {(855 }}$ und der damit einhergehende publizistische Charakter der Literaturhistoriographie lösten sich auf, als die Germanistik als universitäres Fach sich nicht mehr nur auf die „Herstellung altdeutscher Texte ${ }^{\text {} 86}$ konzentrierte, sondern sich auch als Neuere deutsche Literaturgeschichte zu institutionalisieren und professionalisieren begann. ${ }^{87}$ War die Behandlung neuerer Literatur bislang der außerakademischen gelehrten Gesellschaft vorbehalten, so beanspruchte ab der zweiten Hälfte des 19. Jahrhunderts die universitäre Fachwissenschaft diesen Untersuchungsgegenstand für sich. ${ }^{88}$ Wesentlich für die Profilierung „,der ,Neugermanistik' als eines selbstständigen Zweiges der Universitätsphilologie“ war dabei die „Abgrenzung von der ästhetischkritischen und der philosophierenden Rede über Literatur" ${ }^{89}$ Dabei galt es, sich von den Verfassern der große Synthesen bildenden Literaturge-

83 Nämlich durch Friedrichs: Die deutschsprachigen Schriftstellerinnen des 18. und 19. Jahrhunderts (1981).

84 Zur Institutionalisierung der deutschen Literaturgeschichte vgl. Hohendahl: Literarische Kultur im Zeitalter des Liberalismus (1985), bes. S. 266-271.

85 Hohendahl: Literarische Kultur im Zeitalter des Liberalismus (1985), S. 267.

86 Michler: „Das Materiale für einen österreichischen Gervinus“ (1995), S. 188.

87 Zur Einrichtung des ,neueren Fachs' an den Universitäten vgl. Dainat: Von der Neueren Deutschen Literaturgeschichte zur Literaturwissenschaft (1994); Weimar: Geschichte der deutschen Literaturwissenschaft bis zum Ende des 19. Jahrhundert (1989), S. 429-484.

88 Dieser Entwicklung trug die Universität Wien als erste auch institutionell Rechnung, wo, wie erwähnt, 1868 ein zweiter ordentlicher Lehrstuhl für Deutsche Sprache und Literatur eingerichtet wurde.

89 Michler/Schmidt-Dengler: Germanistik in Österreich (2003), S. 200. 
schichten, die den Exaktheitsansprüchen der am Philologiemodell orientierten Neugermanistik nicht mehr genügen konnten, zu distanzieren. Denn: „Literarhistoriker und Dilettant zu sein: diese beiden Prädikate seien als Synonym zu begreifen. ${ }^{\text {"90 }}$ Im Zuge dieser Entwicklung ist das Schreiben von Literaturgeschichten, das im 19. Jahrhundert noch Hochkonjunktur hatte - zwischen 1835 und 1899 erschienen nicht weniger als 199, d.h. im Durchschnitt drei pro Jahr -, zunehmend in die Krise geraten. ${ }^{91}$ Im Übergang zum 20. Jahrhundert drängte die weitere „Ausdifferenzierung des geistesgeschichtlichen Grundmodells in Problem-, Ideenund Stilgeschichte" ${ }^{\prime \prime 2}$ jedoch nicht nur die Literaturhistoriographie zunehmend in die Defensive, sondern auch Autorinnen aus dem Kanon der literaturwissenschaftlichen Untersuchungsgegenstände.

Der Kanon, auf den sich die Neugermanistik berief und von dem sie ihren universitären Legitimitätsanspruch ableitete, war die Weimarer Klassik. Vor allem die Goethe-Philologie, mit der sich die Neugermanistik zunächst als Fach konstituierte, stand im Mittelpunkt des Interesses. ${ }^{93}$ Trotz einiger Kritik an dem neuen Wissenschaftlerselbstverständnis, „Specialist für ein paar classisch-romantische Decennien “94 sein zu wollen, kam man doch immer wieder zu dem Schluss, dass es keinen Sinn mache, „irgend einen Jammerpoeten aus irgend einer Jammerperiode philologisch erschöpfend zu monographieren" ${ }^{\text {"95 }}$. Gegen die „Wissenschaft des nicht Wissenswerten“ wurde jetzt „eine stärkere Konzentration auf das Bedeutungsvolle, auf die großen Autoren und Werke" gefordert. ${ }^{96}$ Überhaupt gewann in Abgrenzung zur und in Erweiterung der kleinteiligen philologischen Arbeit die „Persönlichkeit des Dichters“, das „schöpferische Subjekt“ und nicht zuletzt das „literarische Genie“ zunehmend an Bedeutung. Die "gesammelten Detailerkenntnisse in konzentrierter Form zusammenzufassen und dabei das Charakteristische der Erscheinungen hervorzuheben“ wird damit zur „vornehmste[n] Aufgabe“ des Literaturwissenschaftlers, „weil sie - außer philologischer Schulung - voraussetzt, daß er

90 Fohrmann: Organisation, Wissen, Leistung (1991), S. 117.

91 Vgl. auch die hohe Anzahl von ,Krisentexten' aus dieser Zeit: Dainat/FiedeldeyMartyn: Literaturwissenschaftliche Selbstreflexion (1994).

92 Höppner: Die regionalisierte Nation (2007), S. 31.

93 Vgl. Kruckis: Goethe-Philologie als Paradigma neuphilologischer Wissenschaft im 19. Jahrhundert (1994).

94 Roethe: Gedächtnisrede auf Erich Schmidt (1913), S. 620.

95 Fulda: Ueber historische und ästhetische Betrachtung (1885), S. 677.

96 Dainat: Von der Neueren Deutschen Literaturgeschichte zur Literaturwissenschaft (1994), S. 506. 
das Wesentliche vom Unwesentlichen und Zufälligen zu unterscheiden“ vermag. ${ }^{97}$

Was als ,unwesentlich', was als ,wesentlich' und wer als ,große Dichterpersönlichkeit' zu gelten hatte, stand jedoch schon vor der Konstituierung der Neugermanistik fest. Grundlegend für die Abgrenzung des Kanons, auf den sie sich berief und der ihre Einrichtung als universitäres Fach legitimieren sollte, waren nämlich Vorgänge, die sich nicht im Feld der Wissenschaft, sondern im literarischen Feld selbst vollzogen hatten. Diese Vorgänge, die in der zweiten Hälfte des 18. Jahrhunderts einsetzten, sollten in den darauffolgenden Jahrzehnten den Literaturbetrieb grundlegend verändern. Auch die zur selben Zeit ,auftretenden Behinderungen für Schriftstellerinnen "98 lassen sich, wie zu zeigen sein wird, auf diese Veränderungen zurückführen. Zum einen ermöglichten geänderte Druckbedingungen eine billigere und schnellere Massenproduktion von Büchern, zum anderen wurde durch die zunehmende Alphabetisierung der Bevölkerung Literatur nicht nur Angelegenheit einer elitären Oberschicht, sondern verbreitete sich auch bei durchschnittlich gebildeten Lesern. ${ }^{99}$ Beides zusammen führte zu einer Ausweitung und Kommerzialisierung des Buchmarkts, an dem erstmals auch Schriftstellerinnen in nennenswerter Zahl Anteil hatten. Helga Gallas' und Anita Runges Bibliographie von Romanen und Erzählungen deutscher Autorinnen verzeichnet für die Zeit zwischen 1771 und 1810 immerhin 110 Autorinnen mit 396 Veröffentlichungen. ${ }^{100}$

Gleichzeitig und in scheinbarem Widerspruch zur Egalisierung und Kommerzialisierung des literarischen Feldes etablierte sich aber auch ein neues, selbstbewusstes Autorschafts- und Kunstverständnis. Dabei wurde die „Autorposition [...] durch das Genie besetzt“ und das „Dogma der

97 Dainat: Von der Neueren Deutschen Literaturgeschichte zur Literaturwissenschaft (1994), S. 507.

98 Heydebrand/Winko: Geschlechterdifferenz und literarischer Kanon (1994), S. 133.

99 Vgl. Bürger: Literarischer Markt und Öffentlichkeit am Ausgang des 18. Jahrhunderts in Deutschland (1980), S. 162-212; Fronius: „Nur eine Frau wie ich konnte so ein Werk schreiben" (2007), S. 29-52.

100 Dramen, Autobiographien und Gedichtbände sind bei dieser Zahl nicht berücksichtigt; Gallas/Runge: Romane und Erzählungen deutscher Schriftstellerinnen um 1800 (1993). - 1825 führte Carl Schindel über 500 Schriftstellerinnen an, Sophie Pataky 1898 bereits über 5.000; Schindel: Die deutschen Schriftstellerinnen des 19. Jahrhunderts (1823-1825); Pataky: Lexikon deutscher Frauen der Feder (1898). 
Autonomie von Literatur als Kunst“ propagiert. ${ }^{101}$ Um diese „Literatur mit Kunstanspruch, die sich als autonomes, ästhetisches Medium von Erkenntnis “102 konstituierte, von der weitverbreiteten ,Unterhaltungsliteratur' zu unterscheiden, wurde ein neues Auswahl- und Orientierungsschema notwendig. Gleichsam als Wächter über die „Dichotomisierung von hoher und niederer Literatur "103 entstand die Institution der professionellen Literaturkritik. Mit der wachsenden Zahl an Schriftstellerinnen und deren Erfolg am literarischen Markt setzte aber auch eine vehement geführte Debatte über den Status der literarischen Produktion von Frauen ein, in der es vor allem darum ging, zwischen ,hoher' und ,niederer' Literatur auch geschlechtsspezifisch zu unterscheiden. Wie Christa Bürger gezeigt hat, wurde dabei sehr schnell ein enger Zusammenhang zwischen Dilettantismus und literarischer Tätigkeit von Frauen diskursiv festgeschrieben. ${ }^{104}$ Dieser Engführung von Frau und Dilettantismus kamen zwei historische Erscheinungsformen entgegen, die „für die Kanonchancen der Autorinnen in der Folgezeit von grundlegender Bedeutung " ${ }^{“ 105}$ waren. Dabei handelte es sich um die Zuordnung von Schriftstellerinnen zum unterhaltsam-didaktischen Genre und die „Polarisierung der ,Geschlechtscharaktere ““106 am Ende des 18. Jahrhunderts.

Als Vorbild für das den Frauen zugestandene didaktische Genre galt der - auch von Touaillon eingehend besprochene - erste deutsche Roman einer Schriftstellerin: die 1771 anonym erschiene und äußerst erfolgreiche Geschichte des Fräuleins von Sternheim von Sophie von La Roche. Als Herausgeber fungierte Christoph Martin Wieland, der ein, von Touaillon nicht beachtetes, ausführliches Vorwort verfasste, in dem er Bestimmungen über Literatur von Frauen formulierte, die in den darauffolgenden Jahrzehnten eine ungeahnte Wirkungsmacht entfalten sollten. ${ }^{107}$ Die Verfas-

101 Heydebrand/Winko: Geschlechterdifferenz und literarischer Kanon (1994), S. $134-135$.

102 Heydebrand/Winko: Geschlechterdifferenz und literarischer Kanon (1994), S. 136.

103 Bürger/Bürger/Schulte-Sasse (Hg.): Zur Dichotomisierung von hoher und niederer Literatur (1982).

104 Bürger: Leben Schreiben (1990), S. 19-31.

105 Heydebrand/Winko: Geschlechterdifferenz und literarischer Kanon (1994), S. $139-140$.

106 Hausen: Die Polarisierung der,Geschlechtscharaktere' (1976).

107 Auf die heute so berühmte von Wieland inszenierte Herausgeberfiktion ging Touaillon nicht ein. Vielmehr betonte sie, dass an der Rolle Wielands als Unterstützer und Tadler „nichts Ungewöhnliches, etwa nur bei einer Frauenarbeit Gestattetes" zu bemerken sei, da auch Männer ihre Texte von anderen Männern 
serin selbst, von der Wieland, wie er schrieb, die Handschrift „unter den Rosen der Freundschaft “108, also unter dem Siegel der Verschwiegenheit, erhalten habe, habe nie selbst daran gedacht, „für die Welt zu schreiben, oder ein Werk der Kunst hervorzubringen “109, vielmehr war für sie immer die „moralische Nützlichkeit der erste Zweck" ${ }^{110}$. Deshalb, so beteuerte Wieland, konnte „ich dem Verlangen nicht widerstehen, allen tugendhaften Müttern, allen liebenswürdigen jungen Töchtern unsrer Nation ein Geschenke mit einem Werke zu machen, welches mir geschickt schien, Weisheit und Tugend [...] zu befördern “111. Mit der expliziten Nennung des Adressatenkreises, der Intention der Autorin und der Funktion der Sternheim entwarf Wieland das Genre ,Frauenliteratur' und verwies den Roman sogleich darauf, was La Roches Hervortreten als Autorin zugleich legitimierte, festlegte und beschränkte. ${ }^{112}$ Möglich war das aufgrund der in der zweiten Hälfte des 18. Jahrhunderts aufkommenden Vorstellung der ,Geschlechtscharaktere', derzufolge nicht die gesellschaftliche Stellung, sondern die Natur „de[n] Mann für den öffentlichen, die Frau [aber] für den häuslichen Bereich" ${ }^{113}$ prädestiniere. Während das frühaufklärerische Konzept des ,Gelehrten Frauenzimmers' zumindest zum Teil auf der Annahme der natürlichen Gleichheit der Geschlechter basierte, ging man bei der ,Empfindsamen' von einer natürlichen Ungleichheit aus:

Die Gelehrte war eine Analogiekonstruktion. Im Bild der Empfindsamen dagegen sollten die Spezifika des Weiblichen deutlich hervortreten. Mit ihm war ein dem Männlichen entgegengesetzt gedachter weiblicher Geschlechtscharakter gemeint. ${ }^{114}$

Die Ablehnung der weiblichen Gelehrsamkeit und die Aufwertung des Gefühls als moralische Instanz führten zwar zunächst zu einer Aufwertung der traditionell den Frauen zugeschriebenen sensitiven Eigenschaften, jedoch nur um den Preis der Sektoralisierung. Gleichsam als „Galionsfiguren empfindsamer Tugend“115 und als literarische Repräsentantinnen dieser

korrigieren ließen. Touaillon: Der deutsche Frauenroman des 18. Jahrhunderts (1919), S. 102 (Anm. 107).

108 Wieland: An D. F. G. R. V. ******* [Vorwort des Herausgebers] (1983), S. 9.

109 Wieland: An D. F. G. R. V. ******* [Vorwort des Herausgebers] (1983), S. 13.

110 Wieland: An D. F. G. R. V. ******* [Vorwort des Herausgebers] (1983), S. 14.

111 Wieland: An D. F. G. R. V. ${ }^{* * * * * * *}$ [Vorwort des Herausgebers] (1983), S. 10.

112 Becker-Cantarino: Schriftstellerinnen der Romantik (2000), S. 161; vgl. auch dies.: Meine Liebe zu Büchern (2008).

113 Hausen: Die Polarisierung der ,Geschlechtscharaktere' (1976), S. 367.

114 Bovenschen: Die imaginierte Weiblichkeit (1979), S. 161.

115 Bovenschen: Die imaginierte Weiblichkeit (1979), S. 159. 
Tendenz fungierten weibliche Romangestalten, die gegen Ende des 18. Jahrhunderts wahrlich Konjunktur hatten. ${ }^{116}$

Mit der nunmehr klaren Unterscheidung zwischen männlichen und weiblichen Eigenschaften war eine Grundlage geschaffen, die der literarischen Öffentlichkeit die Möglichkeit bot, gegenüber der neu hinzutretenden Gruppe schreibender Frauen eine autoritäre Kontrollfunktion auszuüben. Diese Kontrollfunktion umfasste sowohl die Produktion und Publikation der Texte von Frauen als auch deren Rezeption. Das Etikett ,Frauenliteratur' wurde dabei zu einem Instrument, um den Handlungsspielraum von Autorinnen zu beschränken und um ihr Schreiben an einen von der patriarchalischen Literatur- und Kulturpolitik disziplinierten Ort zu verweisen. Die wohl berühmteste Rezension, die diese Zuordnungen deutlich ausspricht, ist die Sammelbesprechung von drei von Frauen verfassten Romanen, die Johann Wolfgang Goethe 1806 in der Jenaischen Allgemeinen Literaturzeitung veröffentlichte. Darin empfahl Goethe den „Äußerungen einer weiblichen Feder“ immer die Überprüfung durch einen männlichen Autor,

damit alle Unweiblichkeiten ausgelöscht würden und nichts in einem solchen Werke zurückbliebe, was dem natürlichen Gefühl, dem liebevollen Wesen, den romantischen herzerhebenden Ansichten, der anmuthvollen Darstellung und allem dem Guten, was weibliche Schriften so reichlich besitzen, sich als ein lästiges Gegengewicht anhängen dürfte. ${ }^{117}$

Für ,hohe Literatur mit Kunstanspruch' kamen Romane von Frauen schon allein aufgrund ihres moralischen und didaktischen Charakters nicht in Frage, weshalb sie aus dem Kanon der Schulen und Universitäten fielen. ${ }^{118}$ In Rezensionen wurden sie - wie bei der zitierten Kritik Goethes - häufig nicht einzeln, sondern gesammelt besprochen ${ }^{119}$ und in den populären Literaturgeschichten, die auch weiterhin Literatur von Frauen aufnahmen, wurden sie nicht in den Gang der dargestellten Geschichte integriert, sondern in eigenen Kapiteln zusammengefasst und isoliert: bei Robert Prutz unter „Dichtende Frauen“, bei Georg Weber unter „Frauenliteratur“

116 Dafür spricht auch die große Anzahl an Romanen aus dieser Zeit, deren Titel einfach aus einem weiblichen (Vor-)Namen besteht.

117 Goethe: Anonym, Bekenntnisse einer schönen Seele; Anonym, Melanie das Findelkind; Eleutherie Holberg, Wilhelm Dumont [Rez., 1806] (1901), S. 382 und S. 383-384.

118 Vgl. Heydebrand/Winko: Geschlechterdifferenz und literarischer Kanon (1994), S. $138-139$ und S. $143-145$.

119 Heydebrand/Winko: Geschlechterdifferenz und literarischer Kanon (1994), S. 103. 
und bei Rudolf Gottschall unter „Moderne Anakreontiker und dichtende Frauen“ oder schlicht unter „Die Frauen“. ${ }^{120}$

\section{II.4. Themenwahl und akademische Karriere}

Auch Touaillon durchmaß in ihrer Studie Literaturgeschichten des 19. Jahrhunderts und vermerkte vielfach das Fehlen oder die „nicht ihrer Bedeutung entsprechend[e]" Darstellung von Schriftstellerinnen. (Touaillon 1919, 440) ${ }^{121}$ Betrachtet man aber die zahlreiche, von Touaillon in den Fußnoten ${ }^{122}$ angeführte Forschungsliteratur (insgesamt zitiert sie über 130 Sekundärliteraturtitel, von denen über 110 der universitären sowie außeruniversitären germanistischen Forschungsliteratur zugerechnet werden können), so lässt sich auf den ersten Blick kein Mangel an wissenschaftlichem Interesse für ihr Thema erkennen. Sieht man jedoch genauer hin, so fällt auf, dass sich nur wenige, nämlich 25 der über 110 germanistischen Titel, mit Autorinnen beschäftigen; und von diesen 25 sind nur drei Titel tatsächlich von Universitätsgermanisten: Darunter befinden sich jedoch keine monographisch-umfassenden Darstellungen, sondern akademische Kleinformate - wie eine Rezension ${ }^{123}$ und ein Zeitschriftenaufsatz $^{124}$ - und eine Briefausgabe, nämlich Erich Schmidts Caroline. Briefe aus der Frühromantik, in der ,Caroline' (gemeint ist Caroline Schelling)

120 Prutz: Die deutsche Literatur der Gegenwart (1859), S. 247-270; Weber: Geschichte der deutschen Literatur von ihren Anfängen bis zur Gegenwart (1880), S. 165-168; Gottschall: Die deutsche Nationalliteratur in der ersten Hälfte des neunzehnten Jahrhunderts (1855), Bd. 1, S. 433-448, Bd. 2 (1855), S. $268-$ 293. - Für die Durchsicht der Literaturgeschichten des 19. Jahrhunderts unter diesem Aspekt vgl. auch Brinker-Gabler: Die Schriftstellerin in der deutschen Literaturwissenschaft (1976).

121 Zitat: „Die Literaturgeschichten behandelten Benedicte Naubert nicht ihrer Bedeutung entsprechend. Am ehesten wird ihr noch Koberstein gerecht, [...] die meisten (selbst Hettner) erwähnen sie überhaupt nicht; auch Haym weiß nichts von ihr." - Gemeint sind der 1872 erschienene dritte Band der fünften Auflage von August Kobersteins Grundriß der Geschichte der deutschen Nationalliteratur, Rudolf Hayms Die romantische Schule. Ein Beitrag zur Geschichte des deutschen Geistes von 1870 und Hermann Hettners dreiteilige Literaturgeschichte des 18. Jahrhunderts, deren erste Auflage 1856-1870 und deren sechste Auflage 1912/13 erschien.

122 Ein Literaturverzeichnis erstellte Touaillon nicht. Die hier erwähnten Titel wurden aufgrund der Kurzangaben in den Fußnoten zusammengestellt.

123 Minor: Emil Palleske (Hg.), Charlotte [Rez.] (1880).

124 Seuffert: Der älteste dichterische Versuch von Sophie Gutermann-La Roche (1906). 
aber nicht als Autorin verhandelt wird, sondern als Assistentin und geistige Zuarbeiterin ihres Mannes Friedrich Schelling und als Inbegriff der Muse im Kreis der Romantiker. ${ }^{125}$ Der Großteil der Sekundärtexte stammt von Lehrern, Schriftstellern, Privat- und Universalgelehrten, also von Verfassern, die nicht dem universitären Betrieb angehörten und somit nur einen schwachen Institutionalisierungsgrad aufwiesen. Doch selbst im außerakademischen Bereich fanden die Autorinnen vor allem als Freundinnen und/oder Briefpartnerinnen berühmter Zeitgenossen Beachtung, ${ }^{126}$ wobei die Briefe der männlichen Korrespondenzpartner zumeist publiziert waren, die Gegenbriefe der Autorinnen von Touaillon aber aus den Originalhandschriften zitiert werden mussten. ${ }^{127}$ Auch bei den Primärtexten konnte Touaillon - obwohl das 19. Jahrhundert in der Universitätsgermanistik wahrlich als Jahrhundert der editorischen Großunternehmungen bezeichnet werden kann - nur in zwei von über 240 Fällen auf Neuausgaben zurückgreifen, die jedoch ebenfalls nicht von Universitätsgermanisten besorgt worden waren. ${ }^{128}$ Autorinnen wurden in populären Literaturgeschichten also in eigene Bereiche separiert ${ }^{129}$ und innerhalb der universi-

125 Schmidt (Hg.): Caroline (1913). - Caroline Schelling veröffentlichte unter eigenem Namen nichts, ihre Theaterkritiken, Rezensionen und Übersetzungen erschienen unter dem Namen ihres Mannes Friedrich Schelling.

126 Liebes- und Ehebriefwechsel mit bekannten Schriftstellern waren besonders beliebt; u.a. der von Touaillon verwendete Briefwechsel zwischen Clemens Brentano und Sophie Mereau (Brentano/Mereau: Briefwechsel [1908]). Vgl. aber auch die (ebenfalls von Touaillon benutzte) Ausgabe des nicht-akademischen GoetheForschers Gustav von Loeper (Goethe: Briefe Goethe's an Sophie La Roche und Bettina Brentano [1879]).

127 So zitiert Touaillon z. B. Wielands Briefe an La Roche aus Hassencamp (Hg.): Neue Briefe Chr[istoph] Mart[in] Wielands vornehmlich an Sophie von La Roche (1894); die Briefe La Roches an Wieland aber aus Originalhandschriften in der Königlichen Bibliothek Dresden und im Goethe- und Schillerarchiv in Weimar. Insgesamt lassen sich die Veröffentlichungen von Autorinnenbriefen im 19. und frühen 20. Jahrhundert wegen ihrer weitverstreuten Klein- und Kleinsteditionen zu Recht als „heilloses Durcheinander“ bezeichnen. Becker-Cantarino: Schriftstellerinnen der Romantik (2000), S. 161.

128 Dabei handelt es sich um die (mit einem ,informativen' Untertitel versehene) Edition von Wolzogens Agnes von Lilien des Journalisten und Schriftstellers Ludwig Salomon (Agnes von Lilien. Roman in zwei Bänden von Karoline von Wolzogen, Schillers Schwägerin [1881]) und die Edition von La Roches Fräulein von Sternheim des Hamburger Lehrers Kuno Ridderhoff (La Roche: Geschichte des Fräuleins von Sternheim [1907]).

129 Bezeichnenderweise ist diejenige Literaturgeschichte des 19. Jahrhunderts, auf die sich später auch Universitätsgermanisten beriefen, die einzige, die - mit Ausnahme 
tären Literaturwissenschaft nur selten als Produzentinnen von Literatur und wenn, dann an der äußersten Peripherie wahrgenommen. Wenn Literatur von Frauen aber keinen stabilen Platz im Kanon der universitären Forschungsgegenstände hatte, wie lässt sich dann erklären, dass sich Christine Touaillon, die erste Privatdozentin der Germanistik, gerade mit einem Thema habilitieren konnte, das bislang als genauso wenig wissenschaftsfähig galt wie sie selbst?

Die zeitgenössisch extravagante Themenwahl Touaillons rief ungewöhnlich viel Aufmerksamkeit und Bewunderung, aber auch die Verurteilung durch Fachkollegen hervor. Insgesamt wurde ihre Habilitationsschrift zumindest 14-mal in Tageszeitungen und Fachzeitschriften besprochen: zwölfmal davon ausführlich in einer jeweils eigenen Rezension und zweimal gesammelt in den Überblicken Zur deutschen Geistesgeschichte im Zeitalter des Idealismus und Literaturforschung und Verwandtes. ${ }^{130} \mathrm{Im}$ Sinne der Entwicklung und des Selbstverständnisses der Universitätsgermanistik beanstandeten alle Rezensenten die Beschäftigung mit „dichterischen Persönlichkeiten [...], die sich mangels der noch voll entwickelten Ausdrucksfähigkeit in ihren Werken nicht klar umrissen widerspiegeln "131: „Naturgemäß mußte Frau Touaillon sehr viel berücksichtigen, was im üblen Sinne des Wortes bloß Unterhaltungsliteratur gewesen ist ${ }^{\text {"132 }}$, wodurch „sich in dem neuen Buche die Kleinware über Gebühr hervor[dränge] "133. Am weitesten wagte sich Robert Riemann im Anzeiger für deutsches Altertum und deutsche Litteratur vor, der den Grund für das schriftstelle-

einer halben Seite über Anna Louisa Karsch - keine Autorinnen aufnahm: Gervinus: Geschichte der poetischen National-Literatur der Deutschen (1835-1844).

130 Rezensionen in Tageszeitungen: Hermann Michel (Frankfurter Zeitung), Max Mendheim (Leipziger Illustrirte Zeitung), Dr. Gottlieb (Arbeiter-Zeitung), m. (Neue Freie Presse). - Einzelrezensionen in Fachzeitschriften: [Adolf] v. Grolman (Literaturblatt für Germanische und Romanische Philologie), Harry Maync (Das literarische Echo), Waldemar Oehlke (Literarisches Zentralblatt für Deutschland), Beda Prilipp (Konservative Monatsschrift), Hubert Rausse (Literarischer Handweiser), Rob[ert] Riemann (Anzeiger für deutsches Altertum), A[ugust] Sauer (Euphorion), Oskar Walzel (Göttingische gelehrte Anzeigen). - Sammelrezensionen in Fachzeitschriften: Robert Petsch (Preußische Jahrbücher), Julius Stern (Zeitschrift für Deutschkunde).

131 Prilipp: Christine Touaillon, Der deutsche Frauenroman des 18. Jahrhunderts [Rez.] (1921), S. 247.

132 Walzel: Christine Touaillon, Der deutsche Frauenroman des 18. Jahrhunderts [Rez.] (1921), S. 127.

133 Petsch: Christine Touaillon, Der deutsche Frauenroman des 18. Jahrhunderts [Rez.] (1921), S. 251. 
rische Hervortreten von Frauen „in ihren unglückseligen lebensverhältnissen“ sah und „hinter der scheinbaren kraft" der behandelten Schriftstellerinnen einfach nur „überreiztheit und hysterie“ vermutete. ${ }^{134}$ Doch trotz des von allen Rezensenten geteilten Zweifels daran, ob „die schriftstellerinnen des 18[.] jh.s [überhaupt] bewus[s]t schaffende künstlerinnen waren "135, was die universitäre Beschäftigung mit ihnen erst gerechtfertigt hätte, sprach - bis auf Riemann - kein einziger der genannten Referenten Christine Touaillon die Befähigung zum wissenschaftlichen Arbeiten ab. Vielmehr wurde in dem Buch „ein bedeutsamer Beitrag zur Literaturgeschichte klassischer und romantischer Zeit ${ }^{\text {"136 }}$ gesehen und Touaillon „gründliche[ ] Kenntnis und sichere[ ] Beherrschung des umfänglichen Stoffes, eindringende[r] Fleiß und ruhige[ ], vornehme[ ] Objektivität "137 attestiert. Die einzige Besprechung, die ausschließlich positiv geraten ist, die des Gießener Privatdozenten Adolf von Grolman, spricht der Studie sogar „einen so hohen Wert [zu], dass Ref. ein ernsthaftes Kennenlernen der Literatur des 18. Jahrhunderts ohne gründliche Auseinandersetzung mit diesem Werk für ausgeschlossen häl “' ${ }^{\text {138 }}$.

Unter den 14 Rezensionen sticht eine aufgrund ihrer dialektischen Umsicht, die sowohl das Thema und dessen Behandlung als auch die Situation der Verfasserin in die zeitgenössische Germanistik einzuordnen weiß, besonders hervor. Es ist die Besprechung des Prager Germanistikprofessors August Sauer, den Christine Touaillon bereits im Laufe ihrer beiden langwierigen Habilitationsverfahren um Rat gefragt hatte. Sauer schrieb:

Dieses bedeutende, glänzend und temperamentvoll geschriebene Buch einer gelehrten und gescheiten Frau verdient die größte Beachtung. Nicht ein beliebiges Thema hat sich die Verfasserin zur Bearbeitung gewählt, wie wir sie in Seminarien verteilen oder vorschlagen und wie sie im Fluß der jeweiligen wissenschaftlichen Strömungen als dringend notwendige Baggerarbeit gewünscht oder als zufällig angeschwemmtes Strandgut erbeutet werden; sondern der eigensten Begabung und Überzeugung folgend, hat sie es sich selbst

134 Riemann: Christine Touaillon, Der deutsche Frauenroman des 18. Jahrhunderts [Rez.] (1921), S. 59.

135 Riemann: Christine Touaillon, Der deutsche Frauenroman des 18. Jahrhunderts [Rez.] (1921), S. 62.

136 Walzel: Christine Touaillon, Der deutsche Frauenroman des 18. Jahrhunderts [Rez.] (1921), S. 127.

137 Petsch: Christine Touaillon, Der deutsche Frauenroman des 18. Jahrhunderts [Rez.] (1921), S. 252.

138 Grolman: Christine Touaillon, Der deutsche Frauenroman des 18. Jahrhunderts [Rez.] (1921), S. 17. 
gewählt und von der Durchführung trotz ungeheurer Schwierigkeiten ${ }^{139}$ nicht abgelassen. Ein durch und durch weibliches Buch. Das ist sehr erfreulich. Gerade in unserer Wissenschaft erscheint es als dringend geboten, daß begabte Forscherinnen nicht jede beliebige Arbeit machen, die ein gleichbegabter Mann auch leisten kann [...]. . $^{140}$

Der Wunsch Sauers, dass Wissenschafterinnen nicht dieselben Gebiete bearbeiten wie Wissenschafter, verweist auf den Zusammenhang zwischen Themenwahl und akademischer Karriere. So legitimierte Sauer Touaillons Arbeit dadurch, dass er - in der Logik der Geschlechtscharaktere argumentierend - ihren Forschungsgegenstand als einen ,natürlich weiblichen herausstrich; ihm also einen Ort zuwies, der in der traditionell männlich dominierten Nationalphilologie einen äußerst unsicheren Stellenwert hatte. Diese thematische Marginalisierung beinhaltete gleichzeitig aber auch die Möglichkeit, sich nicht in die Hierarchie der zeitgenössischen Forschungsgegenstände einzuschreiben und damit auf diesem Gebiet mit den männlichen Kollegen nicht direkt in Konkurrenz zu treten. Demnach erlaubte Touaillons Spezialisierung auf randständige Forschungsgebiete die im 18. Jahrhundert bereits implementierte Sektoralisierung weiterzuführen; innerhalb dieses Handlungsspielraums (und nur in diesem) führte sie aber auch zur Akzeptanz auf Ebenen des universitären Feldes, die bislang als unerreichbar gegolten hatten.

Die Festschreibung auf ,frauenspezifische‘ Themen wurde Christine Touaillon in ihrer nur sieben Jahre andauernden Privatdozentinnentätigkeit freilich nicht mehr los. Bereits 1921 hatte sich die Wiener Habilitationskommission von den drei von Touaillon vorgeschlagenen Themen für das Probekolloquium „Unterströmungen im deutschen Roman des 18. Jahrhunderts“, „Karoline Auguste Fischer“ und „Die Entwicklung der deutschen Kinderliteratur" einstimmig für das letztgenannte entschieden. ${ }^{141}$ Für das von Paul Merker und Wolfgang Stammler 1925 herausgegebene Standardwerk Reallexikon der deutschen Literaturgeschichte verfasste sie den Beitrag „Frauendichtung “; ${ }^{142}$ bereits in der zweiten Auflage fehlt jedoch nicht nur Touaillons Artikel, der Bereich ,Frauenliteratur

139 Sauer sprach damit die von Touaillon im Vorwort erwähnte schwierige Materialbeschaffung an, die durch ihren Wohnort, den Ersten Weltkrieg und die Auffindbarkeit der oft nur in Originalausgaben vorhandenen Bücher behindert wurde.

140 Sauer: Christine Touaillon, Der deutsche Frauenroman des 18. Jahrhunderts [Rez.] (1921), S. $737-738$.

141 Protokoll der Kommissionssitzung vom 23. Mai 1921; UAW, Phil. Fak., PA 3462 Christine Touaillon.

142 Touaillon: Frauendichtung (1925). 
wurde als einziger gänzlich gestrichen. ${ }^{143}$ Als einzige Frau war Touaillon in den 1920er Jahren auch an einem weiteren, wenn auch nicht im Zentrum der Universität entstandenen, so doch germanistischen Großunternehmen beteiligt: Im dritten Band der von Johann Willibald Nagl, Jakob Zeidler und Eduard Castle herausgegebenen Deutsch-Österreichischen Literaturgeschichte finden sich zwei Beiträge über Schriftstellerinnen von ihr: der Abschnitt über die Wiener Lyrikerin Ada Christen und der Abschnitt über Bertha von Suttner. ${ }^{144}$ Darüber hinaus veröffentlichte sie ein Kinderbuch, ${ }^{145}$ publizierte Gedichte ${ }^{146}$ und berichtete regelmäßig für das Literarische Echo und Die Literatur über Neuerscheinungen von Frauen. ${ }^{147}$ Dabei handelt es sich um Tätigkeiten, die von ihren männlichen Fachkollegen nicht zu erwarten waren, sodass rückblickend und von dieser Warte aus mit einigem Recht festgestellt werden kann, dass Touaillon „an der Universität nicht hervor[trat ${ }^{\text {“148 }}$.

Die Außenseiterposition ermöglichte aber auch, dass Touaillon Akzente der Neuerung an der Universität setzte: So trug sie dazu bei, dass zum einen zeitgenössische Literatur vermittelt wurde; sie hielt vom Sommersemester 1922 bis zum Wintersemester 1927, ihrem letzten an der Universität, nicht weniger als acht Lehrveranstaltungen über Gegenwartsliteratur. ${ }^{149}$ Zum anderen gab sie den Anstoß zur universitären

143 Erst wieder die dritte Auflage des Lexikons von 1997 verzeichnet einen Beitrag unter dem Titel „Frauenliteratur“, in dem Inge Stephan die Genese und Verwendung des Begriffs historisch analysiert. Stephan: Frauenliteratur (1997).

144 Touaillon: Ada Christen [1930]; dies.: Bertha von Suttner [1930].

145 Touaillon: Das Katzenbüchlein (1925).

146 Etwa das Gedicht „An die Musik“ in der Arbeiter-Zeitung und das sozial-politische Arbeitergedicht „Werktage“ im Deutsch-österreichischen Arbeiterkalender. Touaillon: An die Musik (1924); dies.: Werktage (1925).

$147 \mathrm{Vgl}$. neben den bereits erwähnten Publikationen u. a. Touaillon: Frauenprosa (1922/1923); dies.: Helene Voigt-Diederichs, Auf Marienhoff. Vom Leben und von der Wärme einer Mutter [Rez.] (1925/1926); dies.: Neue Frauenromane (1925/1926).

148 Meissl: Germanistik in Österreich (1981), S. 492 (Anm. 29).

149 SoSe 1922: Moderne Romanströmungen (vom Naturalismus bis zum Expressionismus); WiSe 1922/23: Moderne deutsche Lyrik (von Liliencron bis Werfel); WiSe 1923: Die deutsche Lyrik des 20. Jahrhunderts (Wildgans bis Werfel); WiSe 1924/25: Der expressionistische Roman; WiSe 1925/26: Jakob Wassermann und der moderne deutsche Roman; WiSe 1926/27: Geschichte der deutschen Novelle (von ihren Anfängen bis in die Gegenwart); WiSe 1927/28: Moderne Lyrik (von Liliencron bis Stefan George) und Literaturhistorische Übungen zur modernen Literatur. - Außerdem: WiSe 1921/22: Der Roman der Aufklärung; SoSe 1922: Das naturalistische Drama des 18. Jahrhunderts, Literaturhistorische Übungen; 
Auseinandersetzung mit Literatur von Frauen: Ab den 1920er Jahren waren Dissertationen über Autorinnen nichts Ungewöhnliches mehr. Nachdem bis dahin in Wien insgesamt nur vier Dissertationen über Schriftstellerinnen verfasst worden waren, ${ }^{150}$ promovierten allein an der Wiener Germanistik in den 1920er Jahren zehn und in den 1930er Jahren 19 Studierende mit einer Arbeit über Autorinnen, wobei sich einerseits zeigt, dass es sich ausschließlich um Studentinnen handelte, andererseits, dass ab Mitte der 1930er Jahre verstärkt konservativ-katholische, wie die von Touaillon wenig geschätzte Schriftstellerin Enrica von Handel-Mazzetti, ${ }^{151}$ und dem Nationalsozialismus nahestehende Autorinnen, wie Agnes Miegel, Isolde Kurz oder Helene Raff, bevorzugt wurden. ${ }^{152}$

WiSe 1922/23: Die Anfänge des deutschen Romans im 16. Jahrhundert; WiSe 1923/24: Hans Sachs; WiSe 1924/25: Der deutsche Frauenroman des 18. Jahrhunderts; WiSe 1925/26: Der Roman der Aufklärung und seine Gegenströmungen; WiSe 1926/27: Der Geschichtsroman der Aufklärung und seine Unterströmungen. - Vgl. Vorlesungen an der Universität zu Wien 1921/22-1927/28.

150 Julia Liggi: Amalia Schoppe, geborene Weise (1910); Therese Pupini: Karoline Pichlers Romane (1910); Angela Neumann: Ueber Leben und Werke der Gabriela Batsany geb. Baumberg (1914); Hildegard Eberstaller: Das junge Deutschland und George Sand (1915).

$151 \mathrm{Zu}$ Touaillons Auseinandersetzung mit der katholischen Literaturbewegung vgl. Touaillon: Blut und Liebe (1927); den Streit analysierte Bernhard Doppler: Über das Kunstschaffen der Frau (1986).

152 1920er Jahre: Karoline Umlauf: Sophie Mereau (1921); Friederike Wechsler: Die Menschen in den Romanen der Ricarda Huch (1921); Karoline Demant: Marie von Ebners Kindergestalten (1922); Emilie Behr: Ada Christen (1922); Katharina Helmer: Die Frauenbewegung im Spiegel des deutschen Frauenromans in der Zeit von 1830 bis 1850 (1922); Emma Waldhäusl: Karoline Pichlers Stellung zur zeitgenössischen Literatur mit besonderer Berücksichtigung ihrer Novellendichtung (1922); Amalie Aschkenazy: Die Frauenbewegung im Spiegel des deutschen Frauenromans in der zweiten Hälfte des 19. Jahrhunderts (1924); Gertrud Doublier: Charlotte Wolter und ihr Einfluß auf das Drama ihrer Zeit (1925); Felicitas Jellinek: Die weibliche Selbstbiographie des 18. Jahrhunderts (1925); Antoinette Politzer: Heinrich Seuse und Elsbet Stagel (1926). - 1930er Jahre: Selma Steinmetz: Bettina Brentano (1931); Irmgard Panoff: Therese Huber (1931); Ernestine Zottleder: Das Bild der zeitgenössischen Frau im deutschen Frauenroman vom Naturalismus zur Gegenwart (1932); Anna Piorreck: Malwida von Meysenbug und die geistigen Strömungen des 19. Jahrhunderts (1932); Melanie Lebner: Ada Christen (1933); Elisabeth Beschliesser: Das epische Schaffen der Schriftstellerin Edith Gräfin Salburg (1934); Sylvia Balter: Isolde Kurz (1934); Dorothea Rasp: Mathilde Wesendonck (1934); Gertraud Pranter: Malwida von Meysenbug, ihr Leben und ihre dichterische Persönlichkeit (1935); Bella Birnbaum: Die besondere Art des historischen Romans in Ricarda Huchs „Der große Krieg in Deutschland“ (1935); Hermine Obermann: Lou Andreas 
Marginalisiert blieb Touaillons Forschungstätigkeit trotzdem, wozu innerhalb der zunehmend konservativen und rechtsgerichteten Wiener Universität nicht allein ihre Themenwahl beigetragen haben mag, sondern auch ihre politische Nähe zur Sozialdemokratie. Touaillon setzte nämlich auch nach ihrer Habilitation ihr Engagement in linksgerichteten sozialreformatorischen Unterfangen wie der österreichischen Ethischen Gemeinde, ${ }^{153}$ ihre Mitarbeit bei der Arbeiter-Zeitung, ${ }^{154}$ ihre Tätigkeit in Wiener und Grazer Volksbildungsvereinen ${ }^{155}$ und ihr Eintreten für die bürgerliche Frauenbewegung rund um Rosa Mayreder ${ }^{156}$ fort. Außerdem gehörte sie 1922 zu den Gründungsmitgliedern des Verbandes der akademischen Frauen Österreichs, ${ }^{157}$ innerhalb dessen sie sich um einen politisch linksstehenden Zusammenschluss österreichischer Akademikerinnen bemühte. ${ }^{158}$ Im Unterschied zur Romanistin Elise Richter, der ersten habi-

Salomé (1935); Michaela Rabenlechner: Die Dichterinnen der Befreiungskriege um 1813/14 (1935); Marie Bogner: Die Novellen der Isolde Kurz (1936); Fanni Goldstein: Der expressionistische Stilwille im Werke der Else Lasker-Schueler (1936); Maria Brachtl: Quellen, Aufbau und Stilmittel der Romantrilogie „Frau Maria“ von Enrica von Handel-Mazzetti (1937); Martha Katz: Österreichische Frauendichtung der Gegenwart. Ein Beitrag zur Psychologie der weiblichen Kunst (1937); Friederike Redlich: Das lyrische Schaffen Agnes Miegels (1938); Therese Schüssel: Die Schule der Handel-Mazzetti (1938); Zita Wagner: Das literarische Schaffen Helene Raffs (1938).

153 Von der Ethischen Gemeinde wurde gemeinsam mit der Internationalen Liga für Frieden und Freiheit und dem Verein Volksheim auch die Trauerfeier für Touaillon organisiert, bei der Wilhelm Börner, Robert Franz Arnold und Marianne Zycha, promovierte Germanistin und Touaillons Kollegin im Vorstand des Allgemeinen österreichischen Frauenvereins, die Gedächtnisreden hielten. [Anonym:] Gedenkfeier für Dr. Christine Touaillon [1] (1928); [Anonym:] Gedenkfeier für Dr. Christine Touaillon [2] (1928).

154 Für die Arbeiter-Zeitung besprach Touaillon regelmäßig literarische Neuerscheinungen. Vgl. u.a. Touaillon: Artur Pfungst (1926); dies.: Die Kroismichelin und ihr Cäsar (1927); dies.: Sigrid Undsets historischer Roman (1927).

155 In Wien war Touaillon Vortragende im Volksbildungsverein Volksheim und in Graz im Volksbildungsverein Urania. Vgl. Gernot [Red.]: Fünf Jahre Grazer Urania (1924), S. 80; Volkshochschule Wien Volksheim: Bericht (1928), S. 41 und S. 72; Volkshochschule Wien Volksheim: Bericht (1929), S. 10, S. 25 und S. 78.

156 Während ihrer Wiener Privatdozentinnentätigkeit wohnte Touaillon bei Rosa Mayreder. Vgl. Mayreder: Tagebücher 1873-1937 (1988), S. 246; vgl. auch Mayreder: Christine Touaillon [Nekrolog] (1928).

157 [Anonym:] Verband der akademischen Frauen Österreichs [1] (1922); [Anonym:] Verband der akademischen Frauen Österreichs [2] (1922).

158 Der Verband der akademischen Frauen Österreichs wurde auf Aufforderung der International Federation of University Women (IFUW) von Elise Richter initiiert, 
litierten Frau in Österreich, die immer wieder betonte, dass sie an „die Universität nicht als Frauenrechtlerin “159 gekommen sei und dass sie „peinlich auf Gleichheit" geachtet habe, damit man sie ja nicht als Frau wahrnehme, ${ }^{160}$ trat Touaillon auch in ihrer Funktion als Privatdozentin offensiv für feministische Belange ein. Auf der „Konferenz über Gleichberechtigung der Frauen in Österreich“, die am 19. und 20. März 1927 im Festsaal des Ingenieur- und Architektenvereins in Wien stattfand, sprach sie über das Thema „Hochschulen“ und beklagte öffentlich, dass es im Unterschied zum Studium für Frauen „weniger günstig [...] in der Frage der Gleichberechtigung mit dem akademischen Lehramt" stehe, da es zwar mit „größter Energie und Ausdauer" mittlerweile möglich sei, „die Dozentur zu erlangen [...], aber an die Erlangung der Professur [...] derzeit nicht zu denken" sei. ${ }^{161}$

An der Universität schien man, wie ein Germanisten-Nachruf auf Touaillon, die am 15. April 1928 im Alter von fünfzig Jahren starb, ${ }^{162}$ zeigt, bei dieser streitbaren Privatdozentin zu einer Form der Domestizierung übergegangen zu sein, bei der der im 18. Jahrhundert Autorinnen zugeschriebene Geschlechtscharakter auch auf Wissenschaftlerinnen übertragen wurde. Der langjährige Freund und außerordentliche Titularprofessor für das neuere Fach Robert Franz Arnold, der Touaillon durchaus wohlgesonnen war, hob in seinem Nachruf für die Monatsschrift Die Literatur an Touaillon eine „fast mütterliche Teilnahme an allen, die da leiden“, hervor, betonte, dass sie „für ihre Schützlinge durch dick und dünn“ ging, weshalb „diese Kinderlose [...] viele Kinder [hatte], solche sogar, die früher

jedoch mit einigem Widerstreben, da Richter sich nicht politisch betätigen wollte. Richter legte auch stets Wert darauf zu betonen, dass es sich um eine „,unpolitische Vereinigung" handelte. Richter: Summe des Lebens (1997), S. 100, S. 110 und S. 117-118, Zitat S. 117. - Touaillon hingegen bemühte sich um eine Abgrenzung zu „nationalistische[n]“ Gruppierungen, so z. B. zum Bund österreichischer Frauenvereine, der ihr „zu sehr rechtsorientiert“ war. Brief von Touaillon an Elise Richter vom 30. Mai 1923; ÖNB, Handschriftensammlung, 266/47-2.

159 Richter: Summe des Lebens (1997), S. 110; vgl. auch dies.: Erziehung und Entwicklung (1928), S. 92.

160 Richter: Erziehung und Entwicklung (1928), S. 84.

161 Touaillon: Hochschulen (1927). - Zum Ablauf und zu den Vortragenden der Konferenz vgl. ausführlich [Anonym:] Konferenz über Gleichberechtigung der Frauen in Oesterreich (1927).

162 Zunächst wurde Touaillon mit der Diagnose ,Klimakterium` in die psychiatrische Abteilung der Landesnervenklinik Graz eingewiesen; erst die Obduktion ergab ein Herzleiden als Todesursache. Bubeniček: Wissenschaftlerin auf Umwegen (1987), S. 13. 
geboren waren als die Pflegemutter". Ihre literaturwissenschaftliche Tätigkeit beschrieb er als „Herzenssache“, die sie mit all ihrer „Blutwärme“ erfüllt habe, unterstützt durch „ein der weiblichen Mentalität besonders gemäßes Interesse für das literarische Individuum in Miniaturbildern zumal erzählender und lyrischer und zumal weiblicher Poeten “. ${ }^{163}$ Nach ihrem Tod ist Touaillon der wissenschaftlichen Aufmerksamkeit wieder entschwunden und für die (nicht erhaltene) Autobiographie, die sie über ihre Universitätsjahre verfasste, fand ihr Mann bereits 1929 keinen Verleger mehr. ${ }^{164}$ Eingehendes wissenschaftliches Interesse an Touaillons Habilitationsschrift entwickelte sich erst wieder in den 1970er und 1980er Jahren, ${ }^{165}$ in denen sich die (feministische) Literaturwissenschaft - trotz aller Hochachtung für Touaillons Leistung - an ihrer von Weiblichkeitsstereotypen nicht freien Herangehensweise in ihrer Studie Der deutsche Frauenroman des 18. Jahrhunderts auch abarbeitete. ${ }^{166}$

163 Arnold: Christine Touaillon [Nekrolog] (1928), S. 643-644.

164 Brief von Heinrich Touaillon an die J.G. Cottasche Buchhandlung vom 11. September 1929 [darauf auch die Absage des Verlags vom 14. September 1929]; DLA Marbach. - Für diesen Hinweis danke ich Myriam Richter, Hamburg.

165 Die erste wissenschaftshistorische Auseinandersetzung mit Touaillon stammt von Erich Leitner: Christine Touaillon (1973); 1979 erschien mit einem Vorwort von Enid Gajek außerdem ein Faksimile-Nachdruck der Habilitationsschrift. Die erste umfassendere Auseinandersetzung mit Touaillon unternahm Hanna Bubeničk: Wissenschaftlerin auf Umwegen (1987); vgl. auch Rainer Leitner: Christine Touaillon (1991).

166 So z. B. Renate Möhrmann, die Touaillon Parteilosigkeit vorwirft. Möhrmann: Feministische Ansätze in der Germanistik seit 1945 (1979). 